\title{
Genotype classification and fluorescence visual identification of the Rhizoma Paridis of Paris polyphylla var. yunnanensis based on the SNPs of ITS sequence
}

\section{Chi Gao}

Chengdu University of Traditional Chinese Medicine https://orcid.org/0000-0001-6803-0546

Kaiyuan Zhang

Chengdu University of Traditional Chinese Medicine

Qinghe Wang

Chengdu University of Traditional Chinese Medicine

Ling Zhao

Chengdu University of Traditional Chinese Medicine

Rong Chen

Chengdu Institute of Biology

Hongxiang Yin ( $\nabla$ hongxiangy@126.com )

Original article

Keywords: Paris, polyphylla, var.yunnanensis, rDNA, ITS, Single Nucleotide Polymorphism, Genotypes, Fluorescent visual identification, Adulterant

Posted Date: August 10th, 2020

DOI: https://doi.org/10.21203/rs.3.rs-37342/v2

License: (c) (1) This work is licensed under a Creative Commons Attribution 4.0 International License. Read Full License 


\section{Abstract}

A fluorescent visual identification system of Paris polyphylla var. yunnanensis was established based on internal transcribed spacer barcoding. It is proposed for the first time that $P$. polyphylla var. yunnanensis should be divided into two types of genotypes: $\mathrm{YN}-\mathrm{I}$ and $\mathrm{YN}-\mathrm{II}$ according to single nucleotide polymorphism of internal transcribed spacer. In order to avoid false-negative results, two pairs of specific primers for $\mathrm{YN}-\mathrm{I}$ and $\mathrm{YN}-\mathrm{II}$ were designed, respectively, and specific visual fluorescent identification systems was established by SYBR Green I fluorescent dye was directly introduced into the PCR system which can be observed directly with the naked eye for the green fluorescent color of PCR system. Therefrom, it has realized the rapid and directly visual identification of two genotypes of P. polyphylla var. yunnanensis from its common nine adulterants. This study proposed for the first time the existence of different genotypes on the legal basis of Rhizoma Paridis, and provided a model for the accurate identification of different genotypes.

\section{Introduction}

Paris $L$. is a genus in the generalized family Liliaceae of the order Liliflorae, with 28 species and more than 10 varieties in the world, and 24 species and 7 endemic species in China (Gao et al. 2019; Huang et al. 2019). It is mainly distributed in southwestern China, Vietnam, and Uttarakhand and Manipur of India, Nepal, and Europe (Yang et al. 2015). The dried rhizomes of Paris are widely used in various countries and regions as a medicinal material. Rhizoma Paridis is one of the traditional bulk medicinal materials for nearly 2,000 years in China, which was first recorded in "Sheng Nong's herbal classic" (Chen et al. 2015). Modern pharmacological studies have shown that it has such pharmacological effects as uterine contraction, analgesia, and hemostasis, antitussive and antiasthmatic, immune regulation (Liu et al. 2016; Guan et al. 2019; Zhang et al. 2018). It is mainly used for the treatment of malignant boils, sore throat, snake and insect bite, fall and flutter pain, convulsions, and other symptoms. The herb is an important raw material for famous proprietary Chinese medicines such as "Yunnan Baiyao" and "Kangbingdu granules"(Lin et al. 2019). In the 2020 edition of "Chinese pharmacopeia", P. polyphylla var. chinensis (PPC) and P. polyphylla Smith var. yunnanensis (Franch.) Hand.-Mazz (PPY) are recorded as the authentic species of Rhizoma Paridis.(Committee Chinese Pharmacopoeia 2020). However, in addition to the pharmacopeia varieties, other species in the Paris, such as Paris vaniotii H. Lév. $(P$. vaniotii), Paris fargesii var. fargesii (P. fargesivar) and so on have been also widely used as Rhizoma Paridis in 28 ethnic groups such as Zhuang, Dai, Miao, and Tibetan (Wang et al. 2018; Liu et al. 2019). Modern phytochemistry studies indicate that the dried rhizomes of Paris species mainly contain steroidal saponins, flavonoids, triterpenoid saponins, ecdysis hormone, and other chemical components. The main active ingredient is steroidal saponins are widely distributed in species of the Genus Paris, and there are significant differences in the types, contents, and effects of steroidal saponins among different species (Huang 2018; Kang et al. 2017).

According to Li heng's classification system, PPY belongs to Sect. Euthyra Franch. of the Subgenus Daiswa (Rafinesque-Schmaltz) H. Li, which is mainly distributed in southwest China (Li 1998; Huang et al. 
2019; Luo et al. 2017). Due to the lower natural propagation rate of PPY, the slow natural growth and the longer production cycle of Rhizoma Paridis, the annual demand increases at a rate of $20 \%$, the wild PPY has been plundered for a long time and the resources are on the verge of exhaustion (Duan et al. 2018). After the investigation of the artificial planting base of Rhizoma Paridis in Sichuan and Yunnan province of China, it was found that the cultivation of Rhizoma Paridis was in the primary stage from wild breeding to artificial cultivation, the production and trade of medical material were lack of an industrial standard. And the mixture of certified species recorded in China Pharmacopoeia(CP) and other varieties of Paris L. was common in the cultivation, production, circulation, and so on links because of economic interests. According to the national random inspection on the commodities in recent years, the pass rate of multiple batches of Rhizoma Paridis is less than $30 \%$ (Ju et al. 2019). It is difficult to distinguish PPY with the adulterants according to their phenotypic trait, microscopic characteristics, and chemical composition because the morphological characteristics of the rhizome of Paris species were similar, and the saponin types and contents of the species were widely overlapped. Also, the chemical constituents of the same species varied dynamically in different growth years and different parts of the rhizome (Wang et al. 2015; Chen et al. 2017). This brings great hidden trouble to clinical medication safety. Therefore, it is of great significance for the quality control and drug safety to establish a rapid and accurate method for the identification of PPY with its adulterants in the production and trade of medicinal materials.

Internal transcribed spacer (ITS) is one of the core regions of plant DNA barcoding (Li et al. 2011). In recent years, it has been found that the ITS sequence can provide abundant mutation sites and information sites due to ITS rapid mutation and has become an important molecular marker in the phylogenetic and classification studies of angiosperms with lower taxonomic order (Liu et al. 2014). Guo et, al. (2018) used ITS sequences to identify the origin of cultivated and wild samples of Paridis Rhizoma, and compared the differences between them. It was concluded that the diversity of the varieties in market circulation was caused by the confusion of the origin rather than the artificial domestication. Fang et al. (2016) used ITS barcodes to identify the seeds and seedlings of official and un-official Paridis Rhizoma. Zhu et al. (2010) successfully amplified and sequenced the ITS2 sequences of 11 species of Paridis Rhizoma, and found that the identification success rate of ITS2 for the genus Paris was $100 \%$, which was much higher than the other 5 chloroplast sequences. In the study, universal primers were used to amplify and sequence the ITS sequences of PPY and its common related species. By analyzing single nucleotide polymorphism (SNP) variation rule, it is found that PPY should be divided into two types of genotypes, YN-I and YN-II. When using ITS barcodes to identify PPY and its related species with only one pair of specific primers, one genotype may be detected, but another may be missed. In order to avoid falsenegative results, two genotype-specific primer pairs of PPY were designed and two genotype fluorescence visualization identification methods were established respectively. The system through the macroscopic observation of fluorescent color can realize the rapid and directly visual identification of PPY from its common adulterant products. It can be provided a new idea and way to solve the problem of authenticating the authenticity of the medicines of the same species and related species. Also, the exploration of common problems in the quality evaluation of Chinese medicine that the origin comes from multiple species of the same genus has a significant demonstration significance. 


\section{Materials And Methods}

\section{Plant Materials}

One hundred and eighty-four samples of ten Paris species and subspecies in this experiments, including 34 samples of PPC; 65 samples of PPY; 17 samples of $P$. polyphylla; 10 samples of $P$. stenophylla; 8 samples of $P$. veitnamensis, 5 samples of Paris axialis $\mathrm{H}$. Li (P. axialis); 7 samples of $P$. vaniotii; 22 samples of Paris fargesii var. fargesii ( $P$. fargesii); 13 samples of $P$. thibetica; 3 samples of Paris forrestii (Takht.) H. Li (P. forrestii) were collected from different localities in China (Table 1). All the samples were stored in the College of Ethnomedicine, Chengdu University of Traditional Chinese Medicine, China.

\section{DNA extraction}

The leaves of the Paris species were dried with allochroic silica gel, a $30 \mathrm{mg}$ was weighed, and the total DNA of the samples was extracted according to the extraction steps of the plant group DNA isolation kit (Foregene Co., Ltd.). The rhizomes were ground into a powder, then was passed through No.3 sieve. In the study, the extraction steps of the DNA isolation kit in the plant group were improved, which a $20 \mathrm{mg}$ sample of the material was suspended in cell lysis buffer $(20 \mu \mathrm{L} 75 \%$ a-amylase with protease) and stored at $-4^{\circ} \mathrm{C}$.

\section{DNA amplification and sequencing}

DNA extracts were amplified by ITS-4 (5'-TCCTCCGCTTATTGATATGC-3') and ITS-L (5'TCGTAACAAGGTTTCCGTAGGTC-3') primers of ITS sequence (Jiang et al. 2013). Te following polymerase chain reaction (PCR) steps were conducted: $5 \mu \mathrm{L}$ of 10xEasyTaq buffer, $200 \mu \mathrm{M}$ of deoxyribonucleoside triphosphate (dNTPs); $0.25 \mu \mathrm{M}$ of each primer, $2.5 \mathrm{U}$ of EasyTaq polymerase, $1 \mu \mathrm{L}$ (30ng) of template, and makes up $50 \mu \mathrm{L}$ with distilled water. The mixture was predenatured at $94^{\circ} \mathrm{C}$ for $5 \mathrm{~min}$ and was denatured at $94^{\circ} \mathrm{C}$ for $1 \mathrm{~min}$, then it underwent 32 cycles of $1 \mathrm{~min}$ at $94^{\circ} \mathrm{C}, 1 \mathrm{~min}$ at $56.4^{\circ} \mathrm{C}, 1 \mathrm{~min}$ at $72^{\circ} \mathrm{C}$, and then a final extension for $10 \mathrm{~min}$ at $72^{\circ} \mathrm{C}$. The PCR products $(5 \mu \mathrm{L})$ were detected by using the agarose gel (3\%) electrophoresis method with Nanodrop for quality of DNA and were finally photographed under UV light exposure. The amplified products were directly methods Bidirectional DNA sequencing (Tsing Ke Biotechnology Co. Ltd., Chengdu, China).

\section{Construction of phylogenetic tree (NJ)}

The sequenced ITS region fragments were compared and aligned using MEGA 6.0 and removed unreliable and incomplete base sequences at both ends of the phylogenetic tree of ITS sequences for all samples were constructed by Neighbor-joining (N-J) and check the reliability of topological structure of N$\mathrm{J}$ tree used the bootstrap analysis (BS) with tests of 1000 replicates.

\section{Design and screening of PPY specific primers}


The ITS sequences of PPY related cultivated species: P. polyphylla , P. stenophylla, $P$. vietnamensis, $P$. axialis, $P$. vaniotii, $P$. fargesii, $P$. thibetica, $P$. forrestii were compared using Megalign software in DNASTAR to find out SNP sites with a difference of stability. Then designed specific primers in the unique SNP site

area of PPY by using Primer Premier 5.0 software and amplified the DNA template of Paris samples by PCR with the designed primers. The primer pairs were screened out which Tm difference value less than 5 and secondary structure and low mismatch rate $(\triangle G<7)$ (all primers in Table 2). Finally, the specific primer pairs were screened by the above PCR reaction system, in which the objective band is clear and strong specificity and could effectively identify PPY and other common related species.

\section{Establishment of fluorescence visualization identification system}

Primer concentration, annealing temperature, deoxy-ribonucleoside triphosphate (dNTP) concentration, Taq enzyme dosage, cycle number, and template volume were optimized by the single factor method.In the $25 \mu \mathrm{L}$ reaction system, the parameters of each component were set as follows: Specific primer pairs $(\mu \mathrm{M}): 0.3,0.25,0.2,0.15,0.1$; Annealing temperature $\left({ }^{\circ} \mathrm{C}\right): 58,60.6,62,63.7,66.2,68$; dNTP concentration $(\mu \mathrm{M}): 80,120,200,280$; Taq enzyme dosage $(U): 1,1.5,2.5,3.5$; Number of cycles: $26,28,30,32$, 34;Template volume (ng): 10, 30, 60, 90.PCR reaction steps: $2.5 \mu \mathrm{L}$ of 10×EasyTaq buffer, $200 \mu \mathrm{M}$ of dNTPs; $0.25 \mu \mathrm{M}$ of each primer, $2.5 \mathrm{U}$ of EasyTaq polymerase, $1 \mu \mathrm{L}$ (30ng) of template, and makes up $25 \mu \mathrm{L}$ with distilled water. The mixture was predenatured at $94^{\circ} \mathrm{C}$ for $5 \mathrm{~min}$ and was denatured at $94^{\circ} \mathrm{C}$ for $30 \mathrm{~s}$, then it underwent 30 cycles of $30 \mathrm{~s}$ at $64^{\circ} \mathrm{C}, 30 \mathrm{~s}$ at $72^{\circ} \mathrm{C}$, and then a final extension for $5 \mathrm{~min}$ at $72^{\circ} \mathrm{C}$. The PCR products were stored at $12^{\circ} \mathrm{C}$. $5 \mu \mathrm{L}$ of the PCR reaction product mixed with $6 \times$ Loading buffer, then detected on a $3 \%$ agarose gel electrophoresis stained with Goldview I. and then performed electrophoresis at $220 \mathrm{~V}$ for $7 \mathrm{~min}$ and observed under the gel imaging system. $20 \mu \mathrm{L}$ of the PCR reaction product mixed $1 \mu \mathrm{L}$ of $1000 \times$ SYBR Green Type I fluorescent dye and observed under ultraviolet light at $365 \mathrm{~nm}$.

\section{Methodological validation}

A total of 25 samples as experimental materials including 10 batches of Paris samples from 7 traditional Chinese medicine (TCM) manufacturers with three parallel copies of each batch (except for individuals with less than 3 independent pieces in the batch). The universal DNA extraction method and ITS universal primers were used for DNA extraction and ITS amplification and sequencing, and the ITS sequences were compared using BLAST to determine the primitive plants of the experimental materials.

\section{Results}

\section{Amplification and purity detection of ITS region}

A total of 184 plant samples were used for the amplification of ITS regional fragments. About $700 \mathrm{bp}$ bands were obtained when the PCR products were detected by using the agarose gel electrophoresis method and successfully sequenced and the purity was $1.75-2.11$ by Nanodrop test. 


\section{SNP site analysis and primer screening of ITS sequence of PPY}

When analyzing the ITS sequences of 65 samples from PPY of different habitats, it was found that two genotypes could be classified according to the SNP sites. The diversity of the two genotypes in SNP sites was expressed as 40 sites, which were numbered as $\mathrm{YN}-\mathrm{I}$ and $\mathrm{YN}-\mathrm{II}$ respectively. The specific classification criteria of genotypes were shown in Table 3. Among them, there were 35 samples of YN-I genotypes and 30 samples of YN- II genotypes. There were two specific primer pairs that were designed for the two genotypes to avoid the omission of one of the genotypes and produced false-negative results of the PPY test. After sifting the primers in Table 2, YN-IF2/YN-IR2 and YN-IIF3/YN-IIR21 were determined to be the specific primers pairs for the identification of PPY genotype I and II, respectively.

\section{Construction and analysis of phylogenetic tree $(\mathrm{N}-\mathrm{J}$ tree)}

The phylogenetic tree was shown in Figure 1. Phylogenetic tree results showed that the YN-II genotype of PPY was alone clustered into a large branch, indicating that the intraspecific difference of the ITS sequence of YN-II genotype of PPY is smaller than the interspecific differences, and it can be distinguished with its related species. The YN-I genotype of PPY was clustered into a small branch, and it was clustered into a large branch with $P$. forrestii and part of $P$. stenophylla and $P$. polyphylla, indicating that YN-I genotype of PPY has a close relationship with $P$. forrestii, $P$. stenophylla, and $P$. polyphylla. Also, it would provide more molecular evidence for PPY and $P$. stenophylla are classified as Paris polyphylla Smith. All PPC were clustered into one big branch, but some of them were interspersed with a few $P$. stenophylla and P. polyphylla, and P. stenophylla and P. polyphylla were clustered into several branches respectively, indicating that as the same subvarieties, $P$. stenophylla and $P$. polyphylla had a transitional period of gene differentiation and a large intrarespecific genetic diversity. $P$. fargesii, $P$. thibetica, and $P$. vaniotii were clustered into one branch respectively, indicating that intraspecific genetic distance of ITS of those 3 species sequences is less than interspecific genetic distance and can be distinguished with other related species. $P$. axialis and $P$. vietnamensis were gathered together into a small branch, and then together into a large branch, indicating that the closer relationship between them.

\section{Fluorescence visualization identification system}

The optimized inspection results of the six parameters in the fluorescence visualization identification system of two genotypes of PPY were shown in Fig.2-Fig.7 (YN- $\$ genotype), Fig.8-Fig.13 (YN-II genotype). According to the experimental results, the parameters were selected which the obvious specific band brightness and the condition of avoiding nonspecific band amplification and saving experimental materials were considered synthetically. The PCR reaction system and procedures for the two genotypes of PPY were finally determined as follows:

The PCR steps for the identification of YN- $₫$ genotype of PPY as follows: $2.5 \mu \mathrm{L}$ of $10 \times$ EasyTaq buffer, $280 \mu \mathrm{M}$ of dNTPs, $0.25 \mu \mathrm{M}$ of YN-IF2, $0.25 \mu \mathrm{M}$ of YN-IR2, 2.5U of EasyTaq polymerase, $1 \mu \mathrm{L}$ (30ng) of template, and makes up $25 \mu \mathrm{L}$ with distilled water. The mixture was predenatured at $94^{\circ} \mathrm{C}$ for 5 min and 
was denatured at $94^{\circ} \mathrm{C}$ for 30 s, then it underwent 30 cycles of $30 \mathrm{~s}$ at $64^{\circ} \mathrm{C}, 30 \mathrm{~s}$ at $72^{\circ} \mathrm{C}$, and then a final extension for $5 \mathrm{~min}$ at $72^{\circ} \mathrm{C}$.

The PCR steps for the identification of YN-II genotype of PPY follows $2.5 \mu \mathrm{L}$ of $10 \times$ EasyTaq buffer, $280 \mu \mathrm{M}$ of dNTPs, $0.2 \mu \mathrm{M}$ of YN-IIF3; $0.2 \mu \mathrm{M}$ of YN-IIR21, $1.5 \mathrm{U}$ of EasyTaq polymerase, $1 \mu \mathrm{L}$ (30ng) of template, and make up $25 \mu \mathrm{L}$ with distilled water. The mixture was predenatured at $94^{\circ} \mathrm{C}$ for $5 \mathrm{~min}$ and was denatured at $94^{\circ} \mathrm{C}$ for $30 \mathrm{~s}$, then it underwent 30 cycles of 30 s at $64^{\circ} \mathrm{C}, 30 \mathrm{~s}$ at $72^{\circ} \mathrm{C}$, and then a final extension for $5 \mathrm{~min}$ at $72^{\circ} \mathrm{C}$.

\section{Fluorescent visualization identification of PPY with its common related species}

The fluorescence visualization identification results of PPY with its common related species were shown in Figure 14. In the site-specific PCR identification system, there were only DNA amplification products of PPY with obvious bands in agarose gel, while the common related species had no bands. In the fluorescence visualization identification system after the addition of fluorescent substances, only the DNA amplification products of PPY could emit bright green fluorescence, while other common related species could not emit fluorescence. The results showed that the species-specific primers and PCR amplification system designed for PPY had good specificity and could clearly distinguish PPY and its common relatives.

\section{Results of method applicability verification}

There are three samples (No. 10,11, and 22) from 25 samples of Paris commercial crude drugs that failed to extract the DNA, and ITS bands still were not amplified after the reextraction. Therefore, the DNA of the three samples was not verified using the specific PCR fluorescence identification system. Analysis and comparison of 22 ITS sequences were shown that the main source of commercial medicinal materials was dried rhizomes of Paris and Trillium. There are 6 samples that were identified as PPY, including 2 samples of $Y N-\bigotimes$ genotype (No. 20-21) and 4 samples of YN-II genotype (No. 1-4). The rest samples were identified as $P$. forrestii, $P$. polyphylla, and species of Trillium. The specific information of commercial medicinal materials of Paris was shown in Table 4. As shown in Fig.15, the two samples of the YN-I genotype of PPY (No. 20-21) had obvious bands at 248 bp in the YN-I site-specific PCR system, while the other samples had no bands. In the $\mathrm{YN}-\mathrm{I}$ fluorescence visualization identification system, it has bright green fluorescence, which is distinguished from other non-fluorescent samples. Four samples of the YN-II genotype of PPY (No. 1-4) had obvious bands at $149 \mathrm{bp}$ in the YN-Il site-specific PCR system, while the other samples had no bands. In the YN-II fluorescence visualization identification system, there was an obvious bright green fluorescence, which was clearly distinguished from other nonfluorescent samples. The results were consistent with the sequencing results, indicating that the method is accurate, reliable, and specific.

\section{Discussion}


DNA barcoding technology, as a new molecular identification technology that has been continuously developed in recent years. It has become an important supplement to traditional Chinese medicine identification technology because of its advantages of rapid, accurate, efficient, objective, and free from the change of individual morphological characteristics and the development of biological individual characteristics (Shi et al. 2016). It is widely used in the identification of authentic Chinese medicines, the identification of genuine products and substitutes, the identification of origin, the identification of multiorigin sources and genetic diversity, the identification of age, and so on. It plays an important role in ensuring the safety and effectiveness of traditional Chinese medicine, protecting the genetic diversity of medicinal plants, and finding or expanding new drug sources (Cai et al. 2017; Srivastava et al. 2016). Among them, ITS (ITS1/ITS2) sequence was recommended to be included in the core barcode of seed plants by China Plant Barcode Of Life Group (China Plant BOL Group) in 2011. After a large number of studies, the ITS sequence had been proved to be able to accurately identify the origin of the bulk of Chinese herbal medicines such as Ginseng, Honeysuckle, Notopterygium incisum, Chinese wolfberry, and Rhizoma ligustici (Zhang et al. 2017).

Indeed, DNA barcode technology also has certain limitations. Standard DNA barcodes have better resolution efficiency between genus, but the resolution within the genus is lower, especially the identification of related species of the same genus in the large genera with high rates of adaptive radiation, which is not satisfactory. The identification efficiency of a single DNA barcode is often not ideal, and improperly designed primers can also lead to erroneous results (Hollingsworth et al. 2016; Ballin et al. 2019). For deeply processed proprietary Chinese medicines, the DNA is highly degraded and content is extremely low, so it is very difficult to extract enough DNA template (Xiong et al. 2015; Fang et al. 2018; Raclariu et al. 2018). Besides, for accurate molecular identification of species, it is necessary to establish a complete reference sequence database that can fully reflect the intra-species variation and inter-species differentiation, which is a huge workload and difficult for large genera (Zhang et al. 2019). In the face of the above problems, the application of DNA barcode technology in the identification of traditional Chinese medicine still needs to be continuously improved and developed.

There has been a great deal of controversy in the taxonomy of the Paris genus and its phylogenic relationship has been in a state of ambiguity. In addition to the continuous changes of global climate and geology since the middle ages, the continuous hybridization and geographical migration between related species of Paris genus have resulted in radial expansion of the genetic diversity of species of Paris, which is proved by the continuous discovery of new species in recent years (Ji et al. 2019; Huang et al. 2016; Xu et al. 2019). Rhizoma Paridis is a medicine material that the origin comes from multiple species of the same genus, the mixture of similar species of the same genus has always been an important factor affecting the quality of TCM. And the present situation has undoubtedly added great difficulties to the identification of medicinal plants. With the unremitting efforts of predecessors such as CDDP marker Zhou, et al. (2019), chloroplasts genome coding gene Song et al. (2017), ITS2 molecular regions coupled with high resolution melting analysis Duan et al. (2018), new techniques and methods for the identification of Paris species have been developed continuously. However, current DNA barcoding methods generally require gel electrophoresis, or sequencing and homology analysis (constructed the N-J 
tree) to get results, which was not so intuitive in the actual test work. In this study, the site-specific PCR identification system and fluorescence visualization identification system of PPY were established for the first time. This method significantly reduces the time and costs of electrophoretic detection and DNA introduction. Also, the intuitive results effectively improve the speed and ease of use of the method.

According to previous research such as Tang ling et al. (2013) analyzed 15 phenotypic traits of PPY from 20 populations, Chen Zhong-Su Zhi et al. (2017) used SSR molecular markers to analyze the genetic diversity of PPY in 5 different populations, the results showed that PPY is a complex because of phenotypic diversity. Its performance traits are affected by both environmental factors and genes. SNP refers to an intraspecific or interspecific variation of a single nucleotide base in a genome caused by mutations such as transformation, inversion, insertion, deletion, etc. It has become the third generation molecular marker and is widely used in variety identification and genetic diversity analysis, because of its wide distribution, strong genetic stability, high throughput, and fast detection (Mao et al. 2018). In this study, it was found that there are 40 SNP site variations in PPY from the different populations when sequencing the ITS sequences of 65 samples of PPY. This was consistent with Chen Shilin's statement that the comparison of four reference sequences of ITS2 of PPY with a length of 231 bp showed that there were 27 mutation sites (Chen, et al. 2011). Also, the level of genetic diversity of PPY was relatively high was further verified from SNP analysis. Therefore, this study proposed for the first time that PPY should be divided into two genotypes: YN-I and YN-II according to SNP analysis. In order to give consideration to the identification of PPY with two genotypes and avoid false-negative results, specific primers were designed and fluorescence identification methods were established for PPY with two genotypes (Tang et al. 2012).

The efficiency of extracting DNA from commercial Chinese herbal medicines has always been a major problem in molecular identification. Thus, the methods of DNA extraction still need further study. At the same time, the Chinese herbal medicine industry chain was reminded to strengthen the management of bacteriostasis and the management of storage and logistics. (Wu 2016; Fang, et al. 2013; Mishra, et al. 2016). According to specific fluorescence detection and sequencing analysis of commercial medicinal materials of Rhizoma Paridis, the sources of Rhizoma Paridis on the market were complex, not only illegally related species of Paris but also other species of Trillium. It showed that the Trillium plants have flooded the medicinal material market as adulterant products of Rhizoma Paridis, which is a new phenomenon of adulteration of medicinal materials due to the shortage of resources and the rise of prices in recent years. The entry of a large number of adulterant products into the market will seriously affect the quality and clinical efficacy of Rhizoma Paridis. This result also shows the necessity of establishing an accurate, reliable, and practical authentication system for Rhizoma Paridis.

\section{Abbreviations}

PPC: P. polyphylla var. chinensis; PPY: P. polyphylla Smith var. yunnanensis (Franch.) Hand.-Mazz; ITS: internal transcribed spacer; TCM: traditional Chinese medicine; PCR: polymerase chain reaction; $\mathrm{NJ}$ : 
neighbor-joining; GC: guanine and cytosine; dNTP: deoxy-ribonucleoside triphosphate; BS: the bootstrap analysis; SNP: single nucleotide polymorphism.

\section{Declarations}

\section{Authors' contributions}

$\mathrm{KZ}, \mathrm{RC}$ and $\mathrm{HY}$ were associated designing the research. $\mathrm{CG}, \mathrm{KZ}, \mathrm{QW}, \mathrm{LZ}$ collected samples and conducted molecular biology experiments. GC and KZ analyzed data. CG, KZ, HY, RC wrote the manuscript. HY are corresponding authors. All authors read and approved the final manuscript.

\section{Acknowledgments}

We sincerely appreciate Tsing Ke Biotechnology Co. Ltd., Chengdu, China for providing the service of DNA sequencing technology.

\section{Competing interests}

The authors declare that no one have competing interests.

\section{Availability of data and materials}

All data and conclusions are freely available to non-profit colleges and research institutions.

\section{Consent for publication}

All authors consent for publication.

\section{Author details}

${ }^{1}$ College of pharmacy, Chengdu University of TCM, Chengdu, 611130 , China. ${ }^{2}$ College of Ethnomedicine, Chengdu University of TCM, Chengdu, 611130, China. ${ }^{3}$ Natural Products Research Center, Chengdu Institute of Biology, Chinese Academy of Sciences, Chengdu, 610041, China.

\section{Ethics approval and consent to participate}

This article does not contain any studies with human participants or animals performed by any of the authors.

\section{Funding}

This study was funded by the National Sciences Foundation of China Grant 81573545 , and the technology innovation and research and development project on Chengdu Science and Technology Bureau Grant 2019-YF05-00346-SN. 


\section{References}

Ballin NZ, Onaindia JO, Jawad H, Fernandez-Carazo R, Maquet A(2019) High-resolution melting of multiple barcode amplicons for plant species authentication. Food Control 105:141-150. doi:10.1016/j.foodcont.2019.05.022.

Cai J, Xie S, Zhang G, Liu T, Yang S, Chen J(2017) Current advances in DNA barcoding of medicinal plants. Plant Science Journal 35:452-464. doi:10.11913/PSJ. 2095-0837. 2017. 30452.

Chen C, Zhang H, Tan J, Qi S, He G, You Y(2017) Study on Growth Characteristics and Saponin Content of Paris polyphylla var. yunnanensis (Fr.) Hand. Southwest China Journal of Agricultural Sciences 30:13201324. doi:10.16213/j.cnki.scjas.2017.6.014.

Chen L, Zhen Y, Chen M, Huang L (2015) Research progress on enlargement of medicinal resources of Paridis Rhizome. China Journal of Chinese Materia Medica 40:3121-3124. doi:10.4268/cjcmm20151601.

Chen SL (2011) Molecular identification of DNA barcoding of traditional Chinese medicine. People's medical publishing house, 350-352.

Chen ZSZ, Tian B, Cai CT (2017). Genetic diversity of Paris polyphylla var. yunnanensis by SSR marker. Chinese Traditional and Herbal Drugs 48:1834-1838.doi: 10.7501/j.issn.0253-2670.2017.09.021.

Committee Chinese Pharmacopoeia (2015) The Pharmacopeia Commission of the People's Republic of China. vol 1. Medical Science Press, Beijing, China.

Duan BZ, Wang YP, Fang HL, Xiong C, Li XW, Wang P, Chen SL(2018) Authenticity analyses of Rhizoma Paridis using barcoding coupled with high resolution melting (Bar-HRM) analysis to control its quality for medicinal plant product. Chin Med 13:8. doi:10.1186/s13020-018-0162-4.

Duan B, Ma W, Liu Y, Yang L, Li X(2018) Key Techniques for Pollution-free Cultivation of Rhizoma Dioscoreae. World Chinese Medicine 13:2975-2979. doi:10.3969/j.issn.1673-7202.2018.12.006.

Fang HL, Xia CL, Duan BZ, Li XW (2016). Identification of Seeds and Seedlings of Chinese Medicinal Materials Using DNA Barcoding Technology: A Case Study in Paris polyphylla var. yunnanensis. Journal of Chinese Medicinal Materials 39:986-990.

Fang Q, Wang Y, Peng C, Tang L(2018) Application and Prospect of DNA Barcode Molecular Identification Technology in Traditional Chinese Medicine. Chinese Journal of Experimental Traditional Medical Formulae 24:197-205. doi:10.13422 /j. cnki.syfjx.20182122.

Fang T, Zeng C, Yang J, Li D(2013) Herbarium Collections and iFlora. Plant Diversity 35:687-692. doi:10. 7677/ynzwyj201313185. 
Gao Y, Li D, Guo L, Liu J, Ma S, Zheng J, Zan K (2019) Quality Analysis and Study on Paridis Rhizoma Pieces Based on National Drug Evaluation Sampling Inspection. Chinese Pharmaceutical Affairs 33:754759. doi:10.16153/ j.1002-7777.2019.07.006.

Guan X, Li R, Duan B, Wang Y, Fan M, Wang S, Zhang H, Xia C (2019) Advances in research on chemical constituents and pharmacological effects of Paris genus and prediction and analysis of quality markers Chinese Traditional and Herbal Drugs 50:4838-4852. doi:10.7501/j.issn.0253-2670.2019.19.034

Guo LN, Liu J, Zhu L, Zan K, Zheng J, Ma S C, Li JZ (2018). Original identification of Paridis Rhizoma based on DNA barcoding technology. Chinese Journal of Pharmaceutical Analysis 38:857-866.

Hollingsworth PM, Li DZ, van der Bank M, Twyford AD(2016) Telling plant species apart with DNA: from barcodes to genomes. Philos Trans R Soc Lond B Biol Sci 371: doi:10.1098/rstb.2015.0338.

Huang Y, Li X, Yang Z, Yang C, Yang J, Ji Y(2016) Analysis of Complete Chloroplast Genome Sequences Improves Phylogenetic Resolution in Paris (Melanthiaceae). Front Plant Sci 7:1797. doi:10.3389/fpls.2016.01797.

Huang Y, Zhou N, Yang M, Shen Y, Zhang D (2019) A comparative study of the population genetics of wild and cultivated populations of Paris polyphylla var. yunnanensis based on amplified fragment length polymorphism markers. Ecology and Evolution 9:10707-10722. doi:10.1002/ece3.5589.

Huang YY (2018) Analysis on the chemical constituents from the Rhizome of 15 Paris species, Master, Anhui TCM.

Ji Y, Yang L, Chase MW, Liu C, Yang Z, Yang J, Yang J B,Yi TS(2019) Plastome phylogenomics, biogeography, and clade diversification of Paris (Melanthiaceae). BMC Plant Biol 19:543. doi:10.1186/s12870-019-2147-6.

Jiang L, Sun Q, Zhang C, Zhou N, Li B(2013) Molecular identification of Paridis Rhizoma and its adulterants by ITS sequence analysis. Chinese Journal of New Drugs 22:2439-2444.

Ju BY, Li YM, Zhu HD, Fang YG, Wang R, Chen LM, Gao HM, Wang ZM (2019). Improving Quality Standard of Processed Slices of Paridis Rhizoma of Chinese Pharmacopoeia. Chinese Journal of Experimental Traditional Medical Formulae 25:93-101.

Kang LP, Huang YY, Zhan ZL, Liu DH, Peng HS, Nan TG, Zhang Y, Hao QX, Tang JF, Zhu SD, Yang G, Guo LP, Chen M, Huang LQ(2017) Structural characterization and discrimination of the Paris polyphylla var. yunnanensis and Paris vietnamensis based on metabolite profiling analysis. J Pharm Biomed Anal 142:252-261. doi:10.1016/j.jpba.2017.05.019.

Li H, Su B, Zhang Z, Yang Y(2015) An Assessment on the Rarely Medical Paris Plants in China with Exploring the Future Development of Its Plantation. Journal of West China Forestry Science 44:1-7+15. doi:10.16473/j.cnki. xblykx1972. 2015. 03. 001. 
Li Heng (1998) THE GENUS PARIS (TRILLIACEAE). vol 1. Science Press, Beijing, China.

Lin LT, Uen WC, Choong CY, Shi YC, Lee BH, Tai CJ, Tai CJ (2019) Paris Polyphylla Inhibits Colorectal Cancer Cells via Inducing Autophagy and Enhancing the Efficacy of Chemotherapeutic Drug Doxorubicin. Molecules 24: doi:10.3390/molecules24112102.

Liu T, Li X, Xie S, Wang L, Yang S (2016) RNA-seq analysis of Paris polyphylla var. yunnanensis roots identified candidate genes for saponin synthesis. Plant Divers 38:163-170. doi:10.1016/j.pld.2016.05.002.

Liu Y, Xu F, Fan M, Duan B (2019) The application of Paris in medicine of ethnic minorities. Modernization of Traditional Chinese Medicine and Materia Medica-World Science and Technology 21:449-456. doi:10.11842/wst.2019.03.019.

Luo Y, Dong Y, Zhu C, Peng W, Fang Q, Xu X(2017) Research on suitable distribution of Paris yunnanensis based on remote sensing and GIS. China Journal of Chinese Materia Medica 42:4378-4386.

Mao LY, Long LY, Tan XH, Tan YW, Wei YJ, Yu YP, Bin ZJ, Qin JF, Qian Q, Jin G (2018) Development and Analysis of Dendrobium SNP Based on EST Sequence. Journal of Northeast Forestry University 46:74$80+85$.

Mishra P, Kumar A, Nagireddy A, Mani D N, Shukla A K, Tiwari R, Sundaresan V(2016) DNA barcoding: an efficient tool to overcome authentication challenges in the herbal market. Plant Biotechnol J 14:8-21. doi:10.1111/pbi.12419.

Raclariu AC, Heinrich M, Ichim MC, de Boer H(2018) Benefits and Limitations of DNA Barcoding and Metabarcoding in Herbal Product Authentication. Phytochem Anal 29:123-128. doi:10.1002/pca.2732.

Shi S, Pan M, Wang J, Chen C(2016) Application of molecular identification techniques in Chinese materia medica. Chinese Traditional and Herbal Drugs 47:3121-3126. doi:10.7501/j.issn.0253-

2670.2016.17.027

Song Y, Wang S, Ding Y, Xu J, Li MF, Zhu S, Chen N(2017) Chloroplast Genomic Resource of Paris for Species Discrimination. Sci Rep 7:3427. doi:10.1038/s41598-017-02083-7.

Srivastava S, Sanchita, Bhargava M, Sharma A (2016) "DNA Barcoding of Medicinal Plants," in Medicinal Plants - Recent Advances in Research and Development, Tsay Hsin-Sheng, Shyur Lie-Fen, Agrawal Dinesh Chandra, Wu Yang-Chang, and Wang Sheng-Yang Eds. Singapore: Springer Singapore, pp. 97-127.

Tang LQ, Xiao CL, Wang WP (2012) Research and Application Progress of SNP Markers. Chinese Agricultural Science Bulletin 28:154-158.

Tang L, Wangt YF, Li RY, Yang CY, Li G (2013) Study on Phenotypic Diversity of Paris polyphylla. Smith var. yunnanensis in Different Populations. Chinese Agricultural Science Bulletin 29:89-95. 
Wang X, Chen Z, Yin H(2018) The application of Chonglou in Chinese folk medicine. West China Journal of Pharmaceutical Sciences 33:555-560. doi:10.13375/j. cnki. wcjps.2018. 05.025.

Wang Y, Niu H, Zhang Z, Hu X, Li H(2015) Medicinal values and their chemical bases of Paris. China Journal of Chinese Materia Medica 40:833-839. doi:10.4268 /cjcmm20150511.

Wu L (2016) A DNA Integrated System for Identifing Traditional Medicines-Take AAs-containing Herbs and Discorea nipponica as Examples, doctor, Hubei university of traditional Chinese medicine

Xiong B, Zhao Z, Ni L, Ga W(2015) The application, limitation and prospect of DNA barcoding in the identification of traditional Chinese medicine. Journal of Chinese Medicinal Materials 38:2202-2206. doi:10.13863/j. issn1001-4454. 2015. 10. 047.

Xu Z, Wei N, Tan Y, Shuai P, Ngumbau V, Hu G-W, Wang Q-F(2019) Paris lihengiana (Melanthiaceae: Parideae), a new species from Yunnan, China. Phytotaxa 392:45. doi:10.11646/phytotaxa.392.1.4.

Yang Y, Yang SC, Zhao J, Udikeri S, Liu T (2015) Microbial diversity in Paris polyphylla var. yunnanensis rhizomes of varying ages. Genetics and Molecular Research 14:17612-17621. doi:10.4238/2015.December.21.34.

Zhang C, Huang S, and Yan H(2017) Applications of DNA barcoding in Chinese materia medica identification Chinese Traditional and Herbal Drugs 48:2306-2312. doi:10.7501/j.issn.02532670.2017.11.026

Zhang Q, Bi H, and Xie L (2018) Research Advances in Pharmacological Action and Clinical Applications of Paris Polyphylla. Medical Recapitulate 24:4113-4117. doi:10.3969/j.issn.1006-2084.2018.20.029.

Zhang ZP, Wang XY, Zhang Z, Yao H, Zhang XM, Zhang Y, and Zhang BG(2019) The impact of genetic diversity on the accuracy of DNA barcoding to identify species: A study on the genus Phellodendron. Ecol Evol 9:10723-10733. doi:10.1002/ece3.5590.

Zhou W, Duan Y, Lu C, You J, He Y, Wang Z, Yang X, Yin X, Cheng T, An X, Zhang M(2019) Genetic diversity analysis and germplasm identification of Paris species by CDDP markers Chinese Traditional and Herbal Drugs 50:5033-5039. doi:10.7501/j.issn.0253-2670.2019.20.027

Zhu YJ, .Chen SL, Yao H, Tan R, Song JY, Luo K, and Lu J (2010)DNA barcoding the medicinal plants of the genus Paris. Yao Xue Xue Bao 45:376-82.

\section{Tables}


Table 1: Samples used in this study and the corresponding localities

\begin{tabular}{|c|c|c|c|}
\hline $\begin{array}{l}\text { Sample } \\
\text { code }\end{array}$ & Latin name & Locality & $\begin{array}{l}\text { Collected } \\
\text { parts }\end{array}$ \\
\hline $\mathrm{H} 1$ & Paris polyphylla var. chinensis & Dayi, Sichuan & leaf \\
\hline $\mathrm{H} 2$ & P. polyphylla var. chinensis & Shimian, Sichuan & leaf \\
\hline H3 & P. polyphylla var. chinensis & Pingwu Xiangyan, Sichuan & leaf \\
\hline $\mathrm{H} 4$ & P. polyphylla var. chinensis & Pingwu Mupi, Sichuan & leaf \\
\hline H5 & P. polyphylla var. chinensis & Pengzhou Bailu, Sichuan & leaf \\
\hline $\mathrm{H} 6$ & P. polyphylla var. chinensis & Pengzhou Bailu, Sichuan & leaf \\
\hline H7 & P. polyphylla var. chinensis & Pengzhou Bailu, Sichuan & leaf \\
\hline H8 & P. polyphylla var. chinensis & Ya'an Tianquan, Sichuan & leaf \\
\hline H9 & P. polyphylla var. chinensis & Xingshan Shuiyuesi, Hubei & leaf \\
\hline $\mathrm{H} 10$ & P. polyphylla var. chinensis & PengzhouGexianshan, Sichuan & leaf \\
\hline H11 & P. polyphylla var. chinensis & PengzhouGexianshan,Sichuan & leaf \\
\hline $\mathrm{H} 12$ & P. polyphylla var. chinensis & PengzhouGexianshan,Sichuan & leaf \\
\hline $\mathrm{H} 13$ & P. polyphylla var. chinensis & PengzhouGexianshan,Sichuan & leaf \\
\hline $\mathrm{H} 14$ & P. polyphylla var. chinensis & Dayi Qingxia,Sichuan & leaf \\
\hline $\mathrm{H} 15$ & P. polyphylla var. chinensis & Fengcheng,Jiangxi & leaf \\
\hline $\mathrm{H} 16$ & P. polyphylla var. chinensis & Emeishan Zhongfeng,Sichuan & leaf \\
\hline $\mathrm{H} 17$ & P. polyphylla var. chinensis & Emeishan Zhongfeng,Sichuan & leaf \\
\hline $\mathrm{H} 18$ & P. polyphylla var. chinensis & Ya'an Yingjing,Sichuan & rhizome \\
\hline H19 & P. polyphylla var. chinensis & Ya'an Yanqiao,Sichuan & rhizome \\
\hline $\mathrm{H} 2 \mathrm{O}$ & P. polyphylla var. chinensis & Ya'an Yanchang,Sichuan & rhizome \\
\hline H21 & P. polyphylla var. chinensis & Ya'an Yanchang,Sichuan & rhizome \\
\hline $\mathrm{H} 22$ & P. polyphylla var. chinensis & Xingshan Shuiyuesi,Hubei & rhizome \\
\hline $\mathrm{H} 23$ & P. polyphylla var. chinensis & Dujiangyan,Sichuan & rhizome \\
\hline $\mathrm{H} 24$ & P. polyphylla var. chinensis & Luzhou,Sichuan & rhizome \\
\hline H25 & P. polyphylla var. chinensis & Luzhou,Sichuan & rhizome \\
\hline H26 & P. polyphylla var. chinensis & Chongzhou Jiguanshan,Sichuan & leaf \\
\hline $\mathrm{H} 27$ & P. polyphylla var. chinensis & Nianyang Anxian,Sichuan & leaf \\
\hline
\end{tabular}




\begin{tabular}{|c|c|c|c|}
\hline $\mathrm{H} 28$ & P. polyphylla var. chinensis & Nianyang Anxian,Sichuan & leaf \\
\hline $\mathrm{H} 29$ & P. polyphylla var. chinensis & Beichuan Xiaoba,Sichuan & leaf \\
\hline $\mathrm{H} 30$ & P. polyphylla var. chinensis & Beichuan Xiaoba,Sichuan & leaf \\
\hline H31 & P. polyphylla var. chinensis & Chongzhou Huanyuan,Sichuan & leaf \\
\hline H32 & P. polyphylla var. chinensis & Chongzhou Huanyuan,Sichuan & leaf \\
\hline H33 & P. polyphylla var. chinensis & Liping Long'e Guizhou & leaf \\
\hline H34 & P. polyphylla var. chinensis & Liping Long'e Guizhou & leaf \\
\hline YN1 & P. polyphylla var. yunnanensis & Dafang Shuijing,Sichuan & leaf \\
\hline YN2 & P. polyphylla var. yunnanensis & Dafang Shuijing,Sichuan & leaf \\
\hline YN3 & P. polyphylla var. yunnanensis & Bijie Tianbaqiao,Guizhou & leaf \\
\hline YN4 & P. polyphylla var. yunnanensis & Bijie Tianbaqiao,Guizhou & leaf \\
\hline YN5 & P. polyphylla var. yunnanensis & Bijie Qixingguan,Guizhou & leaf \\
\hline YN6 & P. polyphylla var. yunnanensis & Bijie Qixingguan,Guizhou & leaf \\
\hline *YN7 & P. polyphylla var. yunnanensis & Dafang,Guizhou & leaf \\
\hline *YN8 & P. polyphylla var. yunnanensis & Dafang,Guizhou & leaf \\
\hline *YN9 & P. polyphylla var. yunnanensis & Dafang,Guizhou & leaf \\
\hline *YN10 & P. polyphylla var. yunnanensis & Dafang,Guizhou & leaf \\
\hline *YN11 & P. polyphylla var. yunnanensis & Dafang,Guizhou & leaf \\
\hline *YN12 & P. polyphylla var. yunnanensis & Pu'er,Yunnan & leaf \\
\hline *YN13 & P. polyphylla var. yunnanensis & Pu'er,Yunnan & leaf \\
\hline YN14 & P. polyphylla var. yunnanensis & Pu'er,Yunnan & leaf \\
\hline YN15 & P. polyphylla var. yunnanensis & Pu'er,Yunnan & leaf \\
\hline *YN16 & P. polyphylla var. yunnanensis & Longli,Guizhou & leaf \\
\hline *YN17 & P. polyphylla var. yunnanensis & Longli,Guizhou & leaf \\
\hline *YN18 & P. polyphylla var. yunnanensis & Longli,Guizhou & leaf \\
\hline YN19 & P. polyphylla var. yunnanensis & Xuanwei longchang,Yunnan & leaf \\
\hline YN20 & P. polyphylla var. yunnanensis & Xuanwei longchang,Yunnan & leaf \\
\hline YN21 & P. polyphylla var. yunnanensis & Xuanwei longchang,Yunnan & leaf \\
\hline YN22 & P. polyphylla var. yunnanensis & Xuanwei longchang,Yunnan & leaf \\
\hline
\end{tabular}




\begin{tabular}{|c|c|c|c|}
\hline YN23 & P. polyphylla var. yunnanensis & Xuanwei Xize,Yunnan & leaf \\
\hline YN24 & P. polyphylla var. yunnanensis & Xuanwei Xize,Yunnan & leaf \\
\hline YN25 & P. polyphylla var. yunnanensis & Xuanwei Xize,Yunnan & leaf \\
\hline YN26 & P. polyphylla var. yunnanensis & Xuanwei Xize,yunnan & leaf \\
\hline YN27 & P. polyphylla var. yunnanensis & Xingyi,Guizhou & leaf \\
\hline YN28 & P. polyphylla var. yunnanensis & Changshun Guangshun,Guizhou & leaf \\
\hline YN29 & P. polyphylla var. yunnanensis & Changshun Guangshun,Guizhou & leaf \\
\hline YN30 & P. polyphylla var. yunnanensis & Shimian Tianwan,Sichuan & leaf \\
\hline YN31 & P. polyphylla var. yunnanensis & Shimian Tianwan,Sichuan & leaf \\
\hline YN32 & P. polyphylla var. yunnanensis & Shimian Tianwan,Sichuan & leaf \\
\hline YN33 & P. polyphylla var. yunnanensis & Shimian Tianwan,Sichuan & leaf \\
\hline *YN34 & P. polyphylla var. yunnanensis & Gengma,Yunnan & leaf \\
\hline *YN35 & P. polyphylla var. yunnanensis & Liuzhi,Guizhou & leaf \\
\hline YN36 & P. polyphylla var. yunnanensis & Huili Baiji,Sichuan & leaf \\
\hline *YN37 & P. polyphylla var. yunnanensis & Changshun Guangshun,Guizhou & leaf \\
\hline *YN38 & P. polyphylla var. yunnanensis & Changshun Guangshun,Guizhou & leaf \\
\hline *YN39 & P. polyphylla var. yunnanensis & Jinping,Yunnan & leaf \\
\hline *YN40 & P. polyphylla var. yunnanensis & Dayi Huashuiwan,Sichuan & leaf \\
\hline *YN41 & P. polyphylla var. yunnanensis & Dayi Huashuiwan,Sichuan & leaf \\
\hline *YN42 & P. polyphylla var. yunnanensis & Dayi Huashuiwan,Sichuan & leaf \\
\hline *YN43 & P. polyphylla var. yunnanensis & Anshun,Guizhou & leaf \\
\hline *YN44 & P. polyphylla var. yunnanensis & Anshun,Guizhou & leaf \\
\hline *YN45 & P. polyphylla var. yunnanensis & Gengma,Yunnan & leaf \\
\hline *YN46 & P. polyphylla var. yunnanensis & Liuzhi,Guizhou & leaf \\
\hline *YN47 & P. polyphylla var. yunnanensis & Liuzhi Langdai,Guizhou & leaf \\
\hline *YN48 & P. polyphylla var. yunnanensis & Liuzhi Langdai,Guizhou & leaf \\
\hline *YN49 & P. polyphylla var. yunnanensis & Liuzhi Langdai,Guizhou & leaf \\
\hline *YN50 & P. polyphylla var. yunnanensis & Liuzhi,Guizhou & leaf \\
\hline *YN51 & P. polyphylla var. yunnanensis & Liuzhi,Guizhou & leaf \\
\hline
\end{tabular}




\begin{tabular}{|c|c|c|c|}
\hline *YN52 & P. polyphylla var. yunnanensis & Pengzhou,Sichuan & leaf \\
\hline *YN53 & P. polyphylla var. yunnanensis & Pengzhou,Sichuan & leaf \\
\hline *YN54 & P. polyphylla var. yunnanensis & Pengzhou,Sichuan & leaf \\
\hline YN55 & P. polyphylla var. yunnanensis & Pengzhou,Sichuan & leaf \\
\hline YN56 & P. polyphylla var. yunnanensis & Pengzhou,Sichuan & leaf \\
\hline YN57 & P. polyphylla var. yunnanensis & Pengzhou,Sichuan & leaf \\
\hline YN58 & P. polyphylla var. yunnanensis & Tengchong Mingguang,Yunnan & leaf \\
\hline YN59 & P. polyphylla var. yunnanensis & Tengchong Mingguang,Yunnan & leaf \\
\hline YN60 & P. polyphylla var. yunnanensis & Tengchong Jietou,Yunnan & leaf \\
\hline YN61 & P. polyphylla var. yunnanensis & Tengchong Jietou,Yunnan & leaf \\
\hline YN62 & P. polyphylla var. yunnanensis & Yanyuan Yantang,Sichuan & leaf \\
\hline YN63 & P. polyphylla var. yunnanensis & Yanyuan Yantang,Sichuan & leaf \\
\hline YN64 & P. polyphylla var. yunnanensis & Yanbian Gesala,Sichuan & leaf \\
\hline YN65 & P. polyphylla var. yunnanensis & Yanbian Gesala,Sichuan & leaf \\
\hline DY1 & P. polyphylla var. polyphylla & Chongzhou Goujia,Sichuan & leaf \\
\hline DY2 & P. polyphylla var. polyphylla & Ya'an hanyuan,Sichuan & leaf \\
\hline DY3 & P. polyphylla var. polyphylla & Liangshan Puge,Sichuan & leaf \\
\hline DY4 & P. polyphylla var. polyphylla & Pingwu Xiangyan,Sichuan & leaf \\
\hline DY5 & P. polyphylla var. polyphylla & Wenxian Tielou,Gansu & leaf \\
\hline DY6 & P. polyphylla var. polyphylla & Beichuan Xiaoba,Sichuan & leaf \\
\hline DY7 & P. polyphylla var. polyphylla & Beichuan Xiaoba,sichuan & leaf \\
\hline DY8 & P. polyphylla var. polyphylla & Beichuan Xiaoba,Sichuan & leaf \\
\hline DY9 & P. polyphylla var. polyphylla & Beichuan Xiaoba,Sichuan & leaf \\
\hline DY10 & P. polyphylla var. polyphylla & Beichuan Xiaoba,Sichuan & leaf \\
\hline DY11 & P. polyphylla var. polyphylla & Pengzhou Bailu,Sichuan & leaf \\
\hline DY12 & P. polyphylla var. polyphylla & Pengzhou Bailu,Sichuan & leaf \\
\hline DY13 & P. polyphylla var. polyphylla & Pengzhou Bailu,Sichuan & leaf \\
\hline DY14 & P. polyphylla var. polyphylla & Pengzhou Bailu,Sichuan & leaf \\
\hline DY15 & P. polyphylla var. polyphylla & Pengzhou Bailu,Sichuan & leaf \\
\hline
\end{tabular}




\begin{tabular}{|c|c|c|c|}
\hline DY16 & P. polyphylla var. polyphylla & Pengzhou Bailu,Sichuan & leaf \\
\hline DY17 & P. polyphylla var. polyphylla & Xingshan Shuiyuesi,Hubei & rhizome \\
\hline $\mathrm{XY1}$ & P. polyphylla var. stenophylla & Pengzhou Bailu,Sichuan & leaf \\
\hline $\mathrm{XY} 2$ & P. polyphylla var. stenophylla & Dayi Xiling,Sichuan & leaf \\
\hline XY3 & P. polyphylla var. stenophylla & Chongzhou,Sichuan & leaf \\
\hline $\mathrm{XY4}$ & P. polyphylla var. stenophylla & Gulin,Sichuan & rhizome \\
\hline XY5 & P. polyphylla var. stenophylla & Ya'an,Sichuan & rhizome \\
\hline XY6 & P. polyphylla var. stenophylla & Chongzhou Jiguanshan,Sichuan & leaf \\
\hline XY7 & P. polyphylla var. stenophylla & Chongzhou Jiguanshan,Sichuan & leaf \\
\hline XY8 & P. polyphylla var. stenophylla & Liupanshui Shuicheng,Guizhou & leaf \\
\hline XY9 & P. polyphylla var. stenophylla & Liupanshui Shuicheng,Guizhou & leaf \\
\hline $\mathrm{XY10}$ & P. polyphylla var. stenophylla & Chongzhou Jiguanshan,Sichuan & leaf \\
\hline N1 & $\begin{array}{l}\text { Paris } \\
\text { Vietnamensis (Takht.) H. Li }\end{array}$ & Jinping,Yunnan & leaf \\
\hline N2 & P. veitnamensis & Jinping,Yunnan & leaf \\
\hline N3 & P. veitnamensis & Jinping,Yunnan & leaf \\
\hline N4 & P. veitnamensis & Jinping,Yunnan & leaf \\
\hline N5 & P. veitnamensis & Lao Cai,Vietnam & leaf \\
\hline N6 & P. veitnamensis & Lao Cai,Vietnam & leaf \\
\hline N7 & P. veitnamensis & Phôngsali,Laos & leaf \\
\hline N8 & P. veitnamensis & Phôngsali,Laos & leaf \\
\hline WZL1 & Paris axialis $\mathrm{H} . \mathrm{Li}$ & Beichuan Xiaoba,Sichuan & leaf \\
\hline WZL2 & P. axialis & Beichuan Xiaoba,Sichuan & leaf \\
\hline WZL3 & P. axialis & Chongzhoiu Jiguanshan,Sichuan & leaf \\
\hline WZL4 & P. axialis & Chongzhoiu Jiguanshan,Sichuan & leaf \\
\hline WZL5 & P. axialis & Ya'an Yingjing,Sichuan & leaf \\
\hline PF1 & Paris vaniotii $\mathrm{H}$. Lév. & Chongzhou Goujia,Sichuan & leaf \\
\hline PF2 & P. vaniotii & Dayi Huashuiwan,Sichuan & leaf \\
\hline PF3 & P. vaniotii & Shimian,Sichuan & leaf \\
\hline PF4 & P. vaniotii & Chongzhou Bailuzhen,Sichuan & leaf \\
\hline
\end{tabular}




\begin{tabular}{|c|c|c|c|}
\hline PF5 & P. vaniotii & Chongzhou Bailuzhen,Sichuan & leaf \\
\hline PF6 & P. vaniotii & Chongzhoiu Jiguanshan,Sichuan & leaf \\
\hline PF7 & P. vaniotii & Chongzhoiu Jiguanshan,Sichuan & leaf \\
\hline Q1 & Paris fargesii var. fargesii & Chongzhoiu Yulang,Sichuan & leaf \\
\hline Q2 & P. fargesiivar. fargesii & Chongzhou Goujia,Sichuan & leaf \\
\hline Q3 & P. fargesiivar. fargesii & Pingwu Mupi,Sichuan & leaf \\
\hline Q4 & P. fargesiivar. fargesii & Dayi Huashuiwan,Sichuan & leaf \\
\hline Q5 & P. fargesiivar. fargesii & Pengzhou Bailu,sichuan & leaf \\
\hline Q6 & P. fargesiivar. fargesii & Pengzhou Bailu,sichuan & leaf \\
\hline Q7 & P. fargesiivar. fargesii & Pengzhou Bailu,sichuan & leaf \\
\hline Q8 & P. fargesiivar. fargesii & Laifeng,Hubei & rhizome \\
\hline Q9 & P. fargesiivar. fargesii & $\begin{array}{l}\text { Jinggangshan } \\
\text { Huangyangjie,Jiangxi }\end{array}$ & leaf \\
\hline Q10 & P. fargesii var. fargesii & Chongzhou,Sichuan & leaf \\
\hline Q11 & P. fargesiivar. fargesii & Chongzhou,Sichuan & leaf \\
\hline Q12 & P. fargesiivar. fargesii & Pengzhou Bailu,sichuan & leaf \\
\hline Q13 & P. fargesiivar. fargesii & Pengzhou Bailu,sichuan & leaf \\
\hline Q14 & P. fargesiivar. fargesii & Pengzhou Bailu,sichuan & leaf \\
\hline Q15 & P. fargesii var. fargesii & Pengzhou Bailu,sichuan & leaf \\
\hline Q16 & P. fargesiivar. fargesii & Shuangpai,Hunan & leaf \\
\hline Q17 & P. fargesii var. fargesii & Shuangpai,Hunan & leaf \\
\hline Q18 & P. fargesiivar. fargesii & Chongzhou,Sichuan & leaf \\
\hline Q19 & P. fargesiivar. fargesii & Chongzhou,Sichuan & leaf \\
\hline Q20 & P. fargesii var. fargesii & Laifeng,Hubei & leaf \\
\hline Q21 & P. fargesii var. fargesii & Laifeng,Hubei & leaf \\
\hline Q22 & P. fargesii var. fargesii & Shuicheng,Guizhou & leaf \\
\hline HZ1 & P. thibeticavar. thibetica & Dayi Xiling,Sichuan & leaf \\
\hline $\mathrm{HZ2}$ & P. thibeticavar. thibetica & Pingwu Mupi,Sichuan & leaf \\
\hline HZ3 & P. thibeticavar. thibetica & Wenxian Tielou,Gansu & leaf \\
\hline HZ4 & P. thibeticavar. thibetica & Anxian Gaochuan,Sichuan & leaf \\
\hline
\end{tabular}




\begin{tabular}{|llll|}
\hline HZ5 & P. thibeticavar. thibetica & Anxian Gaochuan,Sichuan & leaf \\
\hline HZ6 & P. thibeticavar. thibetica & Beichuan Xiaoba,Sichuan & leaf \\
\hline HZ7 & P. thibeticavar. thibetica & Beichuan Xiaoba,Sichuan & leaf \\
\hline HZ9 & P. thibeticavar. thibetica & Pengzhou Bailu,sichuan & leaf \\
\hline HZ10 & P. thibeticavar. thibetica & Pengzhou Bailu,sichuan & leaf \\
\hline HZ11 & P. thibeticavar. thibetica & Chongzhou Jiguanshan,Sichuan & leaf \\
\hline HZ12 & P. thibeticavar. thibetica & Emeishan,Sichuan & leaf \\
\hline HZ13 & P. thibeticavar. thibetica & Emeishan,Sichuan & leaf \\
\hline CZ1 & Paris forrestii (Takht.) H. Li & Tengchong,Yunnan & leaf \\
\hline CZ2 & P. forrestii & Tengchong,Yunnan & leaf \\
\hline CZ3 & P. forrestii & Tengchong,Yunnan & rhizome \\
\hline
\end{tabular}


Table 2: PPY primer sequence

\begin{tabular}{|c|c|c|c|c|c|}
\hline Primers category & name & sequence $\varangle 5^{\prime}-3^{\prime} \rrbracket$ & dsDNA & TM & GC\% \\
\hline \multirow{12}{*}{$\begin{array}{l}\text { Former primer } \\
\text { YN-I }\end{array}$} & YN-IF1 & CACTCGCCGTGTCCGTCTA & 19 & 60 & 63.2 \\
\hline & & & & & \\
\hline & YN-IF11 & CCACTCGCCGTGTCCGTCTA & 20 & 64 & 65 \\
\hline & YN-IF2 & ACTTTTGACCCACGGGCA & 18 & 59.1 & 55.6 \\
\hline & YN-IF21 & AACACTTTTGACCCACGAGCA & 21 & 60.5 & 47.6 \\
\hline & YN-IF22 & AACACTTTTGACCAACAGGCA & 21 & 61 & 45.5 \\
\hline & YN-IF23 & CAACACTTTTGACCCACAGGCA & 22 & 63.2 & 50 \\
\hline & YN-IF24 & CACTTTTGACCCACGGGCA & 19 & 62.2 & 57.9 \\
\hline & YN-IF3 & CACTTTTGACCCACGGGCA & 19 & 61.9 & 55 \\
\hline & YN-IF31 & GTCGCAATGCTAGGCAACA & 19 & 60.2 & 57.9 \\
\hline & YN-IF4 & GTCGCAATGCTAGGCACCA & 18 & 64 & 61.1 \\
\hline & YN-IF5 & GCGTGCCCTTTGCCGAAT & 22 & 63.5 & 45.5 \\
\hline \multirow{12}{*}{$\begin{array}{l}\text { After the primer } \\
\text { YN-I }\end{array}$} & YN-IR1 & AAACATAAGGCGACGGCATCAT & 19 & 59.6 & 57.9 \\
\hline & YN-IR11 & CAACTATGCCCGTGGGTCA & 20 & 59 & 55 \\
\hline & YN-IR2 & CCAACTATGCTCGTGGGTCA & 23 & 59.9 & 47.8 \\
\hline & YN-IR21 & CTGTCATTAGATGATGCAGTGGC & 23 & 59.5 & 47.8 \\
\hline & YN-IR22 & CTGTCATTAGATGAAGCAGACGC & 24 & 61 & 45.8 \\
\hline & YN-IR23 & ACTGTCATTAGATGATGCAGTGGC & 25 & 61.8 & 48 \\
\hline & YN-IR24 & СTCTCTGATTAGATGATGTAGCGGC & 25 & 63.6 & 48 \\
\hline & YN-IR3 & CACTGTCATTAGATGATGCAGTGGC & 20 & 59.6 & 55 \\
\hline & YN-IR31 & GAAGAGTGGGATGCCAACGT & 21 & 61.7 & 52.4 \\
\hline & YN-IR4 & TGAAGAGTGGGATGCCAAGGT & 24 & 60.7 & 41.7 \\
\hline & YN-IR5 & GTAGCGAAATGCGATACTTGATGT & 21 & 62.6 & 54.5 \\
\hline & YN-IR6 & GCGTCGCTCTGTGCCTACTAT & 23 & 63.2 & 43.5 \\
\hline Former primer & YN-IIF1 & AACGGATGACGATTATGGTGGAA & 20 & 63 & 60 \\
\hline YN-II & & & & & \\
\hline
\end{tabular}




\begin{tabular}{|c|c|c|c|c|c|}
\hline & YN-IIF2 & CGCACAAGAACACGGGAGGT & 21 & 60.9 & 47.6 \\
\hline & YN-IIF21 & GCATCGGCTAATGACAATGGA & 21 & 60.3 & 47.6 \\
\hline & YN-IIF22 & GCATCGGCTAATGACAAAGGA & 23 & 60.6 & 43.5 \\
\hline & YN-IIF3 & CTGCATCGGCTAATGACAATGTA & 20 & 62.4 & 60 \\
\hline & YN-IIF31 & CACTCGCCGTGTTGGTCTCA & 20 & 59.2 & 60 \\
\hline & YN-IIF4 & САCTCGCCGTACTGGTCTCA & 18 & 63.7 & 66.7 \\
\hline & YN-IIF41 & CCTACCGCGCGCACAAGA & 18 & 62.5 & 66.7 \\
\hline \multirow{9}{*}{$\begin{array}{l}\text { After the primer } \\
\text { YN-II }\end{array}$} & YN-IIR1 & CCTACCGCCCGCACAAGA & 20 & 60.4 & 55 \\
\hline & YN-IIR2 & AAGCCAAAGCCСCTACACCT & 21 & 62.6 & 57.1 \\
\hline & YN-IIR21 & GCCTGGGCGTCACGTCTTATA & 23 & 62.9 & 52.2 \\
\hline & YN-IIR22 & CTGCCTGTGCGACACGTCTTATA & 23 & 59.8 & 47.8 \\
\hline & YN-IIR23 & CTGCCTTCGTGACACAACTTCTA & 25 & 60.1 & 44 \\
\hline & YN-IIR24 & GCCTACATGGTCGTAACGTCTTATA & 21 & 63.7 & 57.1 \\
\hline & YN-IIR25 & GCCTGGGGGTCACGACTTTTA & 21 & 63.1 & 61.9 \\
\hline & YN-IIR26 & GCCTGGGGGTCACGACTTCTA & 20 & 60.4 & 60 \\
\hline & YN-IIR3 & CCTGGGGGTCACGACTTGTA & 19 & 61.2 & 57.9 \\
\hline
\end{tabular}


Table 3: SNP sites of two genotypes in PPY

\begin{tabular}{|c|c|c|c|c|c|c|c|c|c|c|c|}
\hline \multirow[t]{2}{*}{ Genotypes } & \multicolumn{11}{|c|}{ Variation sites(bp) } \\
\hline & 9 & 10 & 34 & 36 & 42 & 55 & 62 & 93 & 127 & 131 & 180 \\
\hline YN-I & $\mathrm{T}$ & $G$ & C & $\mathrm{T}$ & C & $T$ & A & C & $G$ & $A$ & $\mathrm{~T}$ \\
\hline \multirow[t]{2}{*}{ YN-II } & $C$ & $\mathrm{~T}$ & $\mathrm{~T}$ & C & $\mathrm{T}$ & C & G & $\mathrm{T}$ & $A$ & $\mathrm{~T}$ & C \\
\hline & 183 & 193 & 197 & 201 & 211 & 212 & 223 & 395 & 411 & 412 & 413 \\
\hline YN-I & G & $A$ & $\mathrm{C}$ & C & A & $T$ & C & $\mathrm{T}$ & G & $C$ & $\mathrm{G}$ \\
\hline \multirow[t]{2}{*}{ YN-II } & $A$ & G & $\mathrm{T}$ & $\mathrm{T}$ & C & C & $\mathrm{T}$ & C & $A$ & $\mathrm{~T}$ & A \\
\hline & 439 & 443 & 462 & 471 & 476 & 482 & 500 & 520 & 521 & 526 & 527 \\
\hline YN-I & G & $A$ & $\mathrm{~T}$ & G & $\mathrm{T}$ & C & C & G & $\mathrm{T}$ & G & G \\
\hline \multirow[t]{2}{*}{ YN-II } & $A$ & G & $C$ & A & C & $\mathrm{T}$ & $\mathrm{T}$ & $\mathrm{T}$ & G & $\mathrm{C}$ & A \\
\hline & 594 & 596 & 599 & 604 & 612 & 615 & 622 & & & & \\
\hline YN-I & $A$ & G & $A$ & A & G & C & $\mathrm{T}$ & & & & \\
\hline YN-II & $\mathrm{G}$ & C & G & $\mathrm{G}$ & $\mathrm{T}$ & $\mathrm{T}$ & C & & & & \\
\hline
\end{tabular}


Table 4: Information table of commercial medicinal materials of Paris

\begin{tabular}{|c|c|c|c|}
\hline Sample number & Merchant-batch & Latin name & Locality \\
\hline 1 & KY-1 & P. polyphylla var. yunnanensis & Yun'nan \\
\hline 2 & KY-1 & P. polyphylla var. yunnanensis & Yun'nan \\
\hline 3 & $\mathrm{KY}-2$ & P. polyphylla var. yunnanensis & Yun'nan \\
\hline 4 & $\mathrm{DH}-1$ & P. polyphylla var. yunnanensis & Yun'nan \\
\hline 5 & $\mathrm{DH}-2$ & Trillium camschatcense & Yun'nan \\
\hline 6 & $\mathrm{DH}-2$ & Trillium camschatcense & Yun'nan \\
\hline 7 & $\mathrm{DH}-2$ & Trillium camschatcense & Yun'nan \\
\hline 8 & FJ-1 & Paris forrestii & Yun'nan \\
\hline 9 & FJ-1 & Paris forrestii & Yun'nan \\
\hline 10 & FJ-1 & - & Yun'nan \\
\hline 11 & FJ-2 & - & Yun'nan \\
\hline 12 & FJ-2 & Trillium govanianum & Yun'nan \\
\hline 13 & FJ-2 & P. forrestii & Yun'nan \\
\hline 14 & JYK & Trillium govanianum & Yun'nan \\
\hline 15 & JYK & Trillium undulatum & Yun'nan \\
\hline 16 & JYK & Trillium govanianum & Yun'nan \\
\hline 17 & SST & Trillium camschatcense & Yun'nan \\
\hline 18 & SST & Trillium camschatcense & Yun'nan \\
\hline 19 & SST & Trillium camschatcense & Yun'nan \\
\hline 20 & YQJ & P. polyphylla var. yunnanensis & Sichuan \\
\hline 21 & YQJ & P. polyphylla var. yunnanensis & Sichuan \\
\hline 22 & YQJ & - & Sichuan \\
\hline 23 & WJ & P. polyphylla & Sichuan \\
\hline 24 & WJ & P. polyphylla & Sichuan \\
\hline 25 & WJ & P. polyphylla & Sichuan \\
\hline
\end{tabular}

\section{Figures}




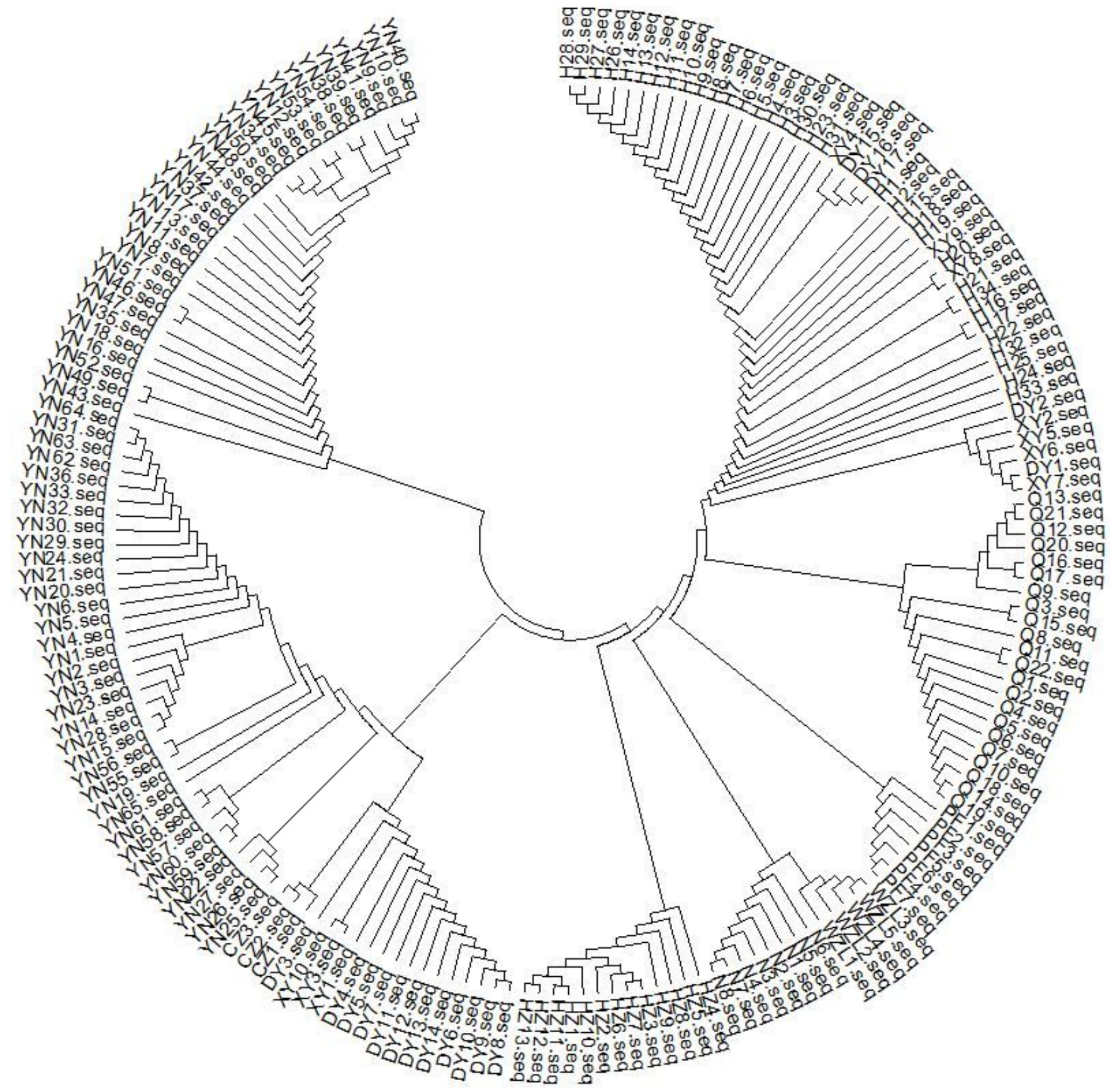

Figure 1

Phylogenetic tree of the Paris genusconstructed based on ITS. 


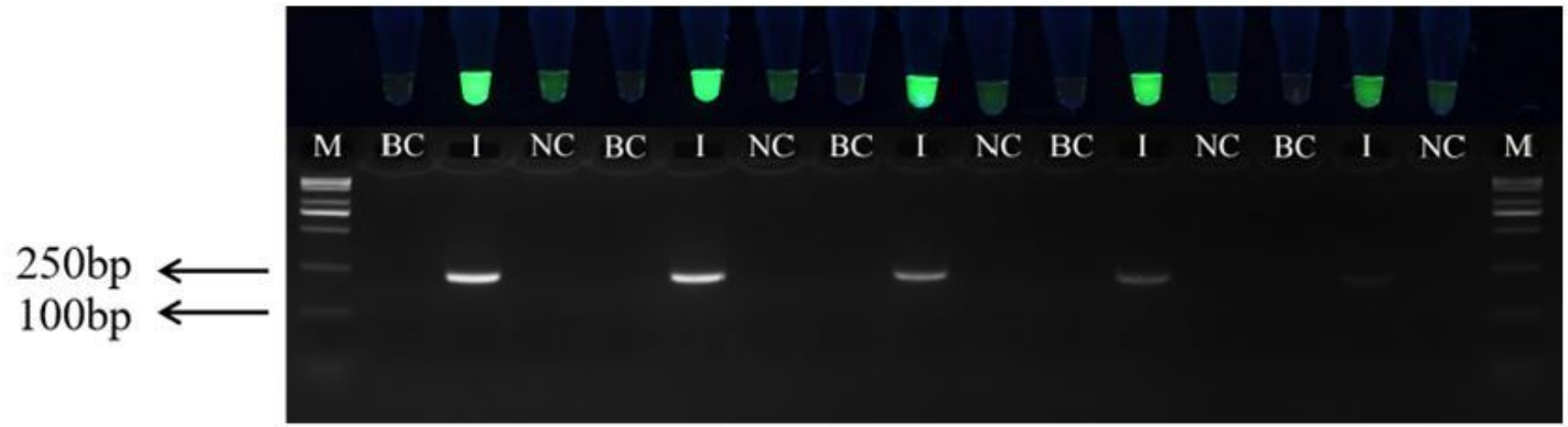

\section{Figure 2}

Investigate into primer concentration of specific PCR systemin YN-I.M: Trans2K Plus DNA Marker. BC: blank control. I: PPY (YN-I). NC: P. polyphylla, the same as below in this chapter. In the figure, the specific primer pairs were $0.3 \mu \mathrm{M}, 0.25 \mu \mathrm{M}, 0.2 \mu \mathrm{M}, 0.15 \mu \mathrm{M}$, and $0.1 \mu \mathrm{M}$, respectively.

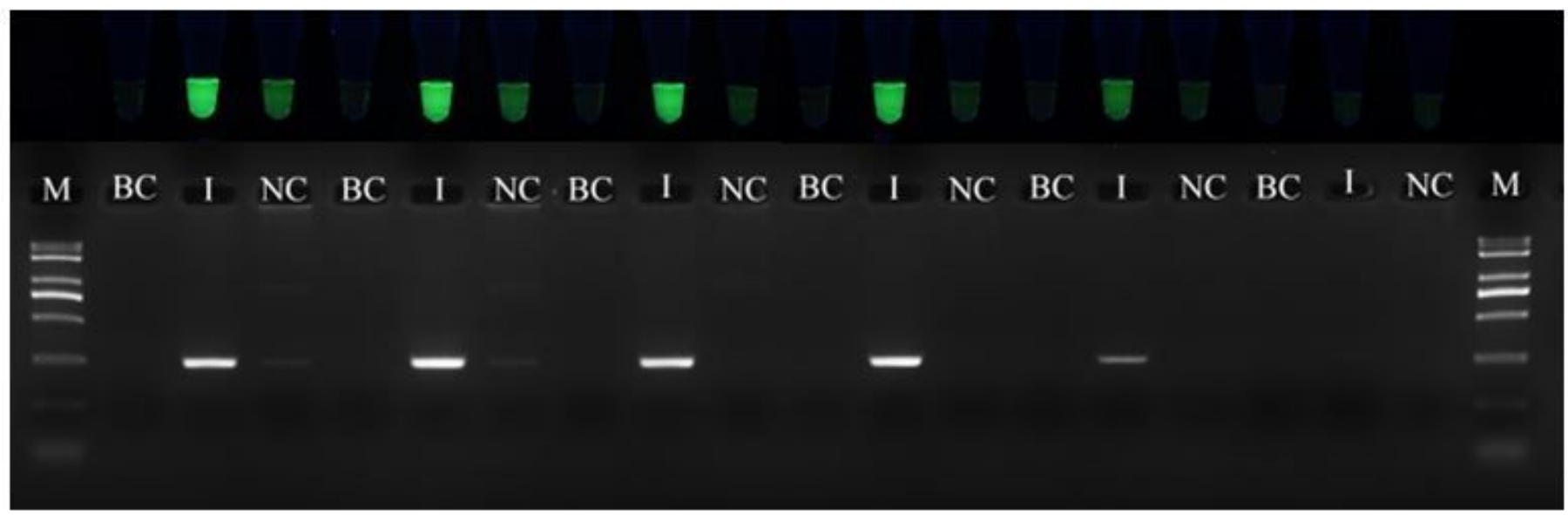

\section{Figure 3}

Investigate into annealing temperature of specific PCR systemin $\mathrm{YN}-\mathrm{I}$. The annealing temperatures were $58^{\circ} \mathrm{C}, 60.6^{\circ} \mathrm{C}, 62^{\circ} \mathrm{C}, 63.7^{\circ} \mathrm{C}, 66.2^{\circ} \mathrm{C}$, and $68^{\circ} \mathrm{C}$, respectively. 


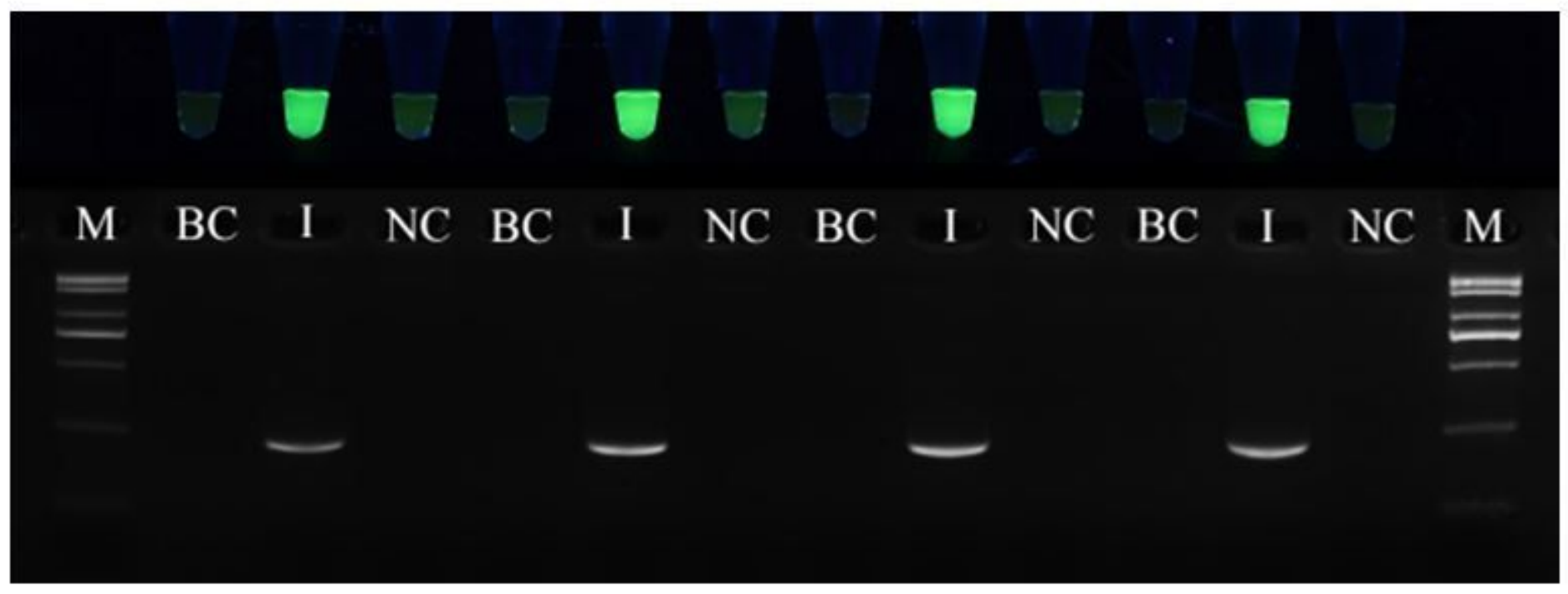

\section{Figure 4}

Investigate into dNTP concentration of specific PCR systemin YN-I. dNTP concentration was $80 \mu \mathrm{M}$, $120 \mu \mathrm{M}, 200 \mu \mathrm{M}$, and $280 \mu \mathrm{M}$, respectively.

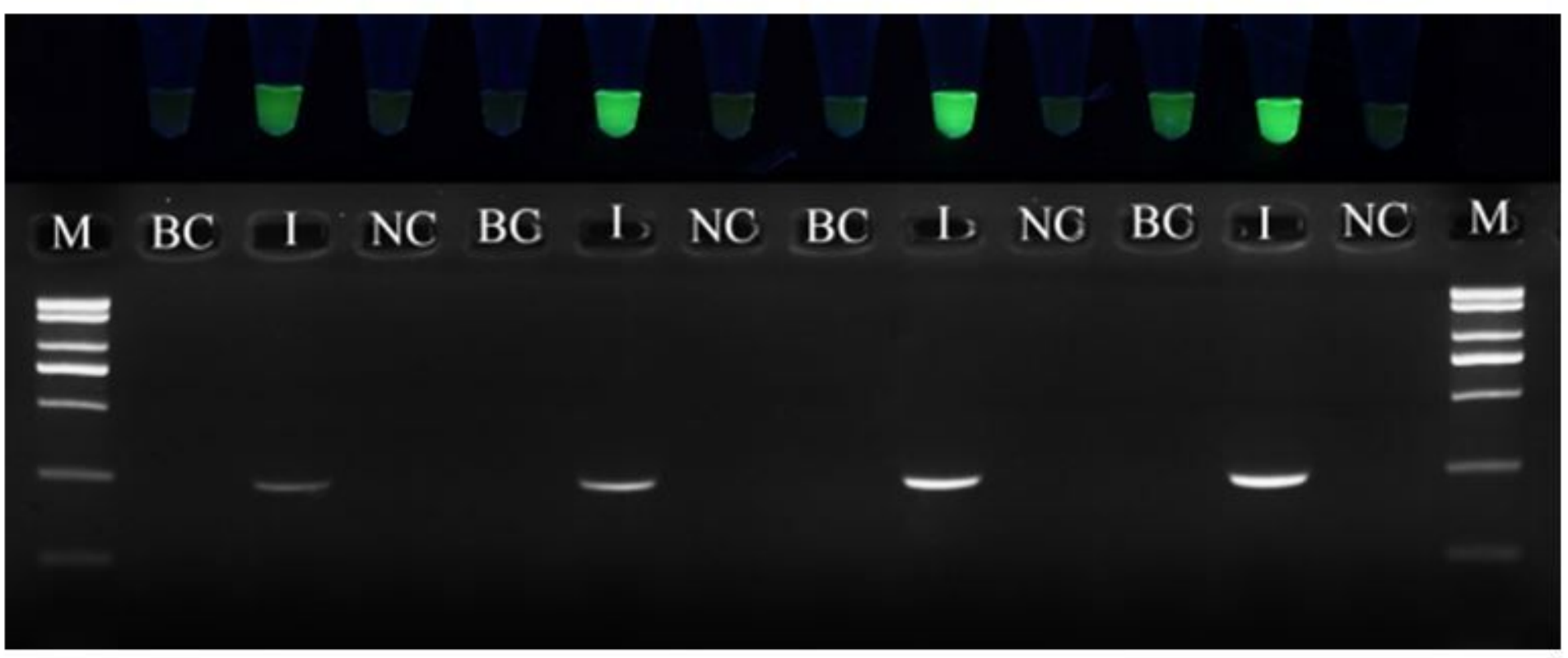

\section{Figure 5}

Investigate into aq enzyme dosage of specific PCR systemin YN-I. The Taq enzyme dosage was $1 \mathrm{U}, 1.5 \mathrm{U}$, $2.5 \mathrm{U}$, and $3.5 \mathrm{U}$, respectively. 


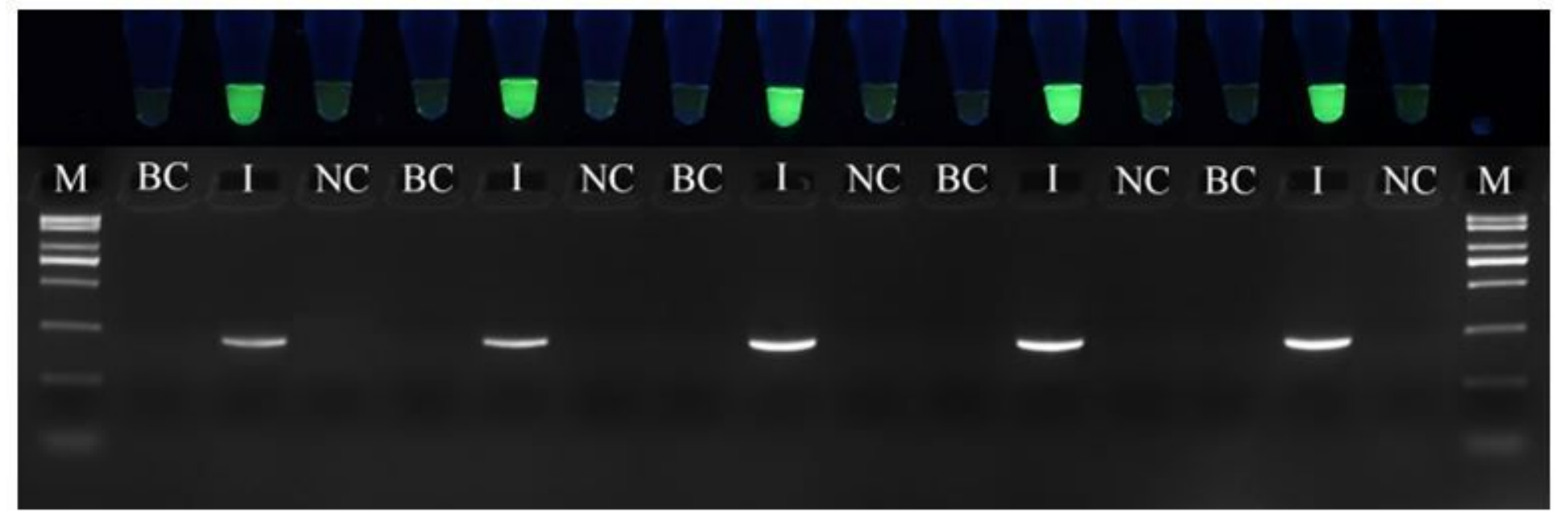

\section{Figure 6}

Investigate into the number of cycles of specific PCR systemin YN-I. The number of cycles was $26,28,30$, 32,34 , respectively.

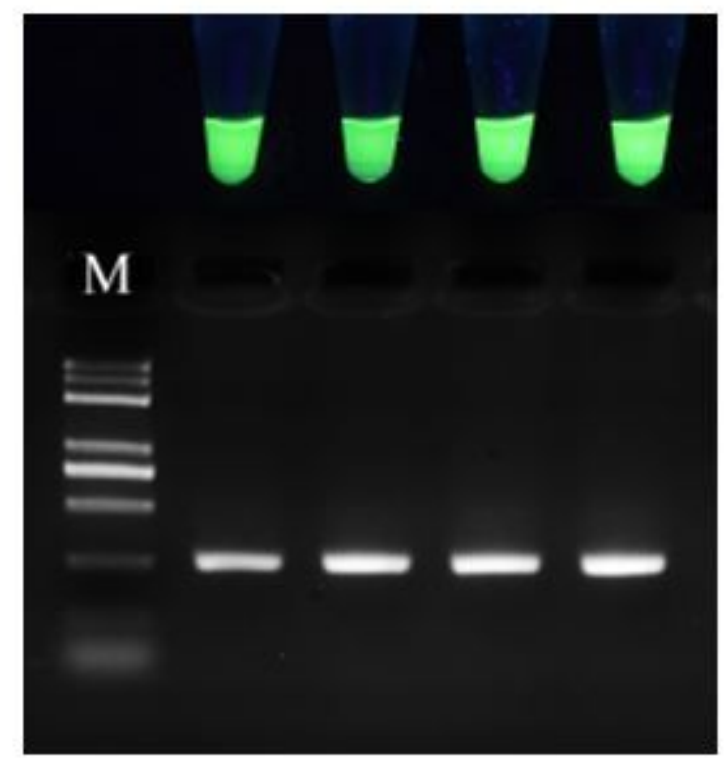

\section{Figure 7}

Investigate into the template quantities of specific PCR systemin YN-I. The template quantities were 10ng, $30 \mathrm{ng}$, 60ng, and 90ng, respectively. 


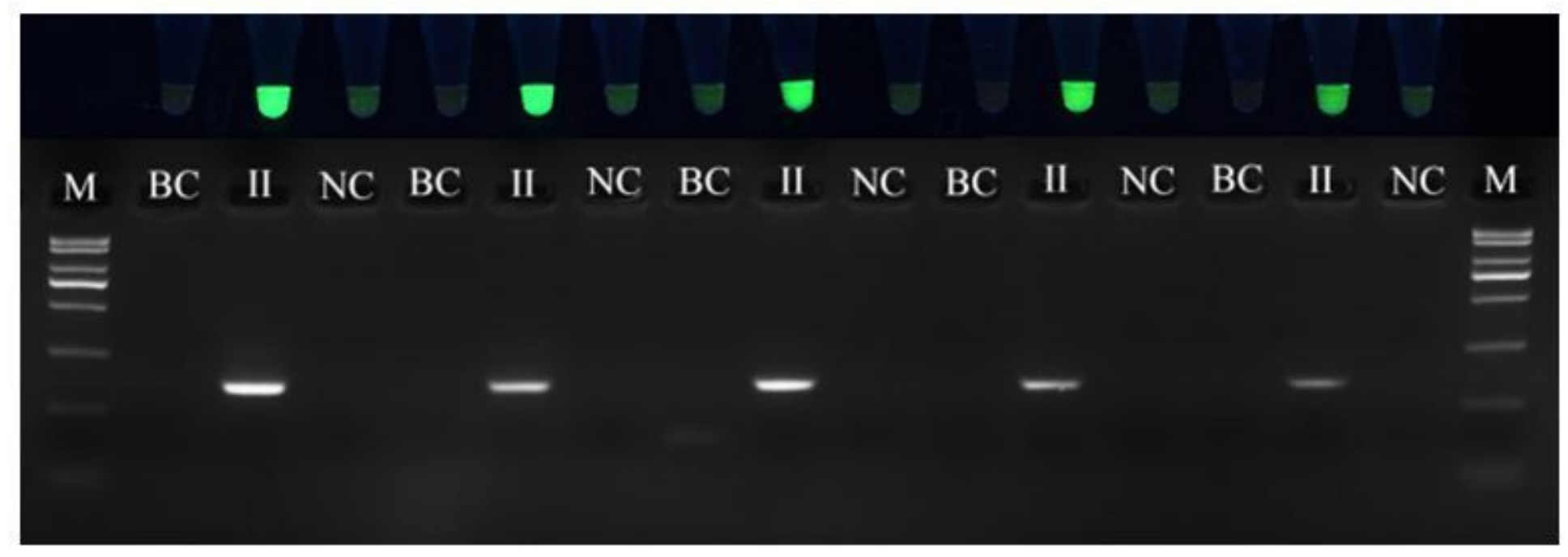

\section{Figure 8}

Investigate into primer concentration of specific PCR systemin YN-II. The specific primer pairs were $0.3 \mu \mathrm{M}, 0.25 \mu \mathrm{M}, 0.2 \mu \mathrm{M}, 0.15 \mu \mathrm{M}$, and $0.1 \mu \mathrm{M}$, respectively.

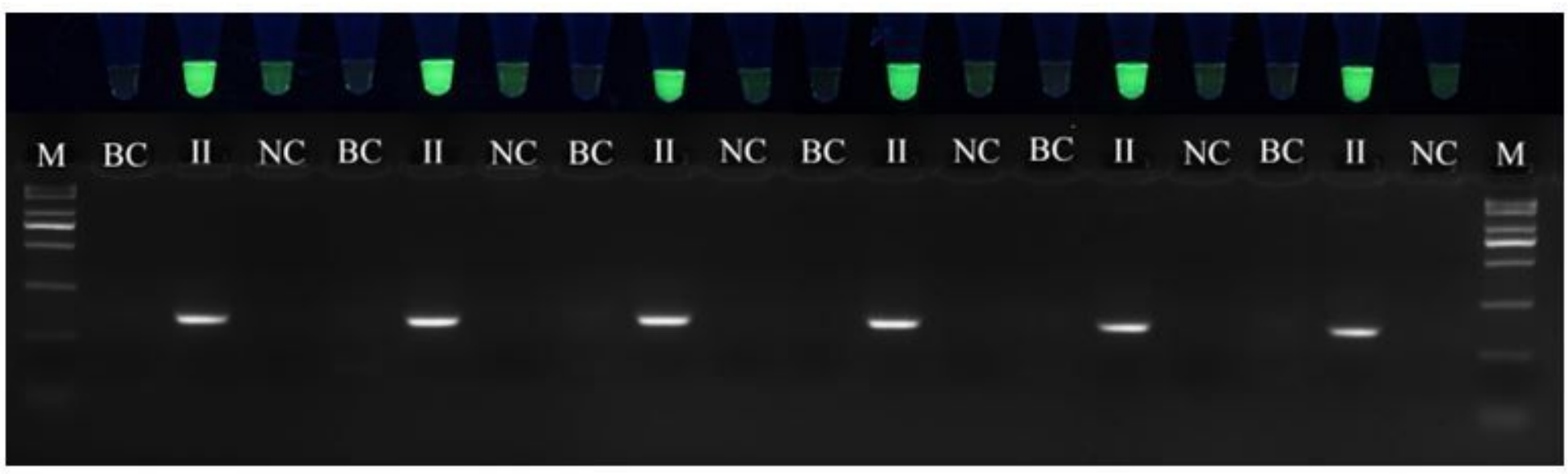

\section{Figure 9}

Investigate into annealing temperature of specific PCR systemin YN-II. The annealing temperatures were $58^{\circ} \mathrm{C}, 60.6^{\circ} \mathrm{C}, 62^{\circ} \mathrm{C}, 63.7^{\circ} \mathrm{C}, 66.2^{\circ} \mathrm{C}$, and $68^{\circ} \mathrm{C}$, respectively. 


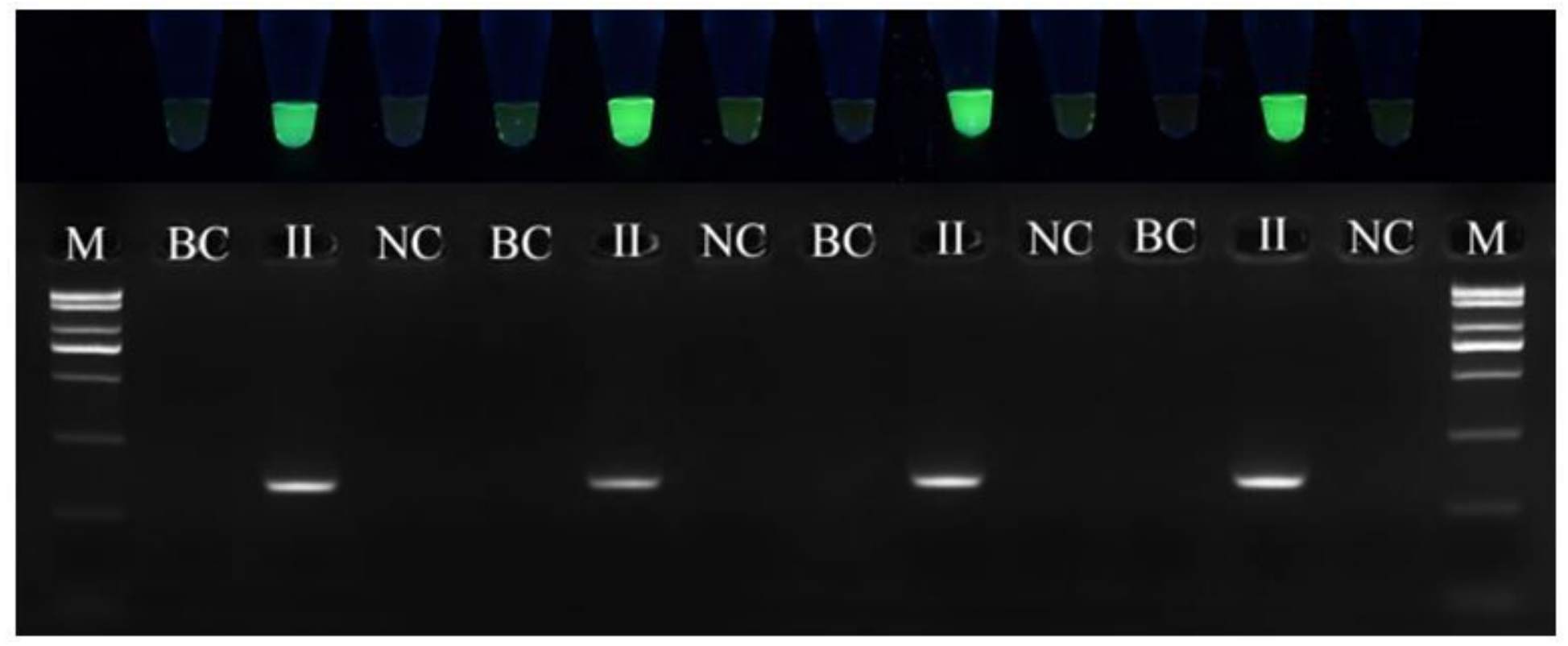

Figure 10

Investigate into dNTP concentration of specific PCR systemin YN-II. dNTP concentration was $80 \mu \mathrm{M}$, $120 \mu \mathrm{M}, 200 \mu \mathrm{M}$, and $280 \mu \mathrm{M}$, respectively.

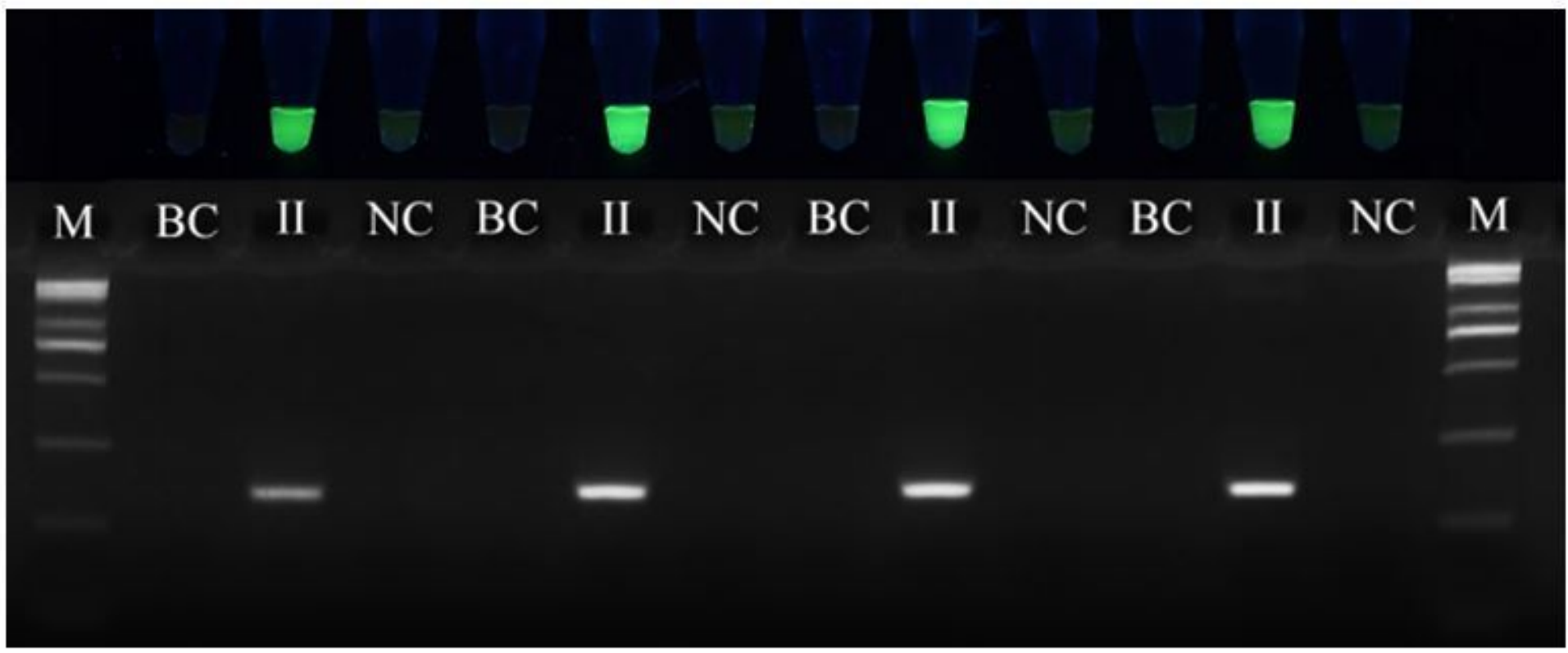

Figure 11

Investigate into aq enzyme dosage of specific PCR systemin YN-II. The Taq enzyme dosage was 1U, 1.5U, $2.5 \mathrm{U}$, and $3.5 \mathrm{U}$, respectively. 


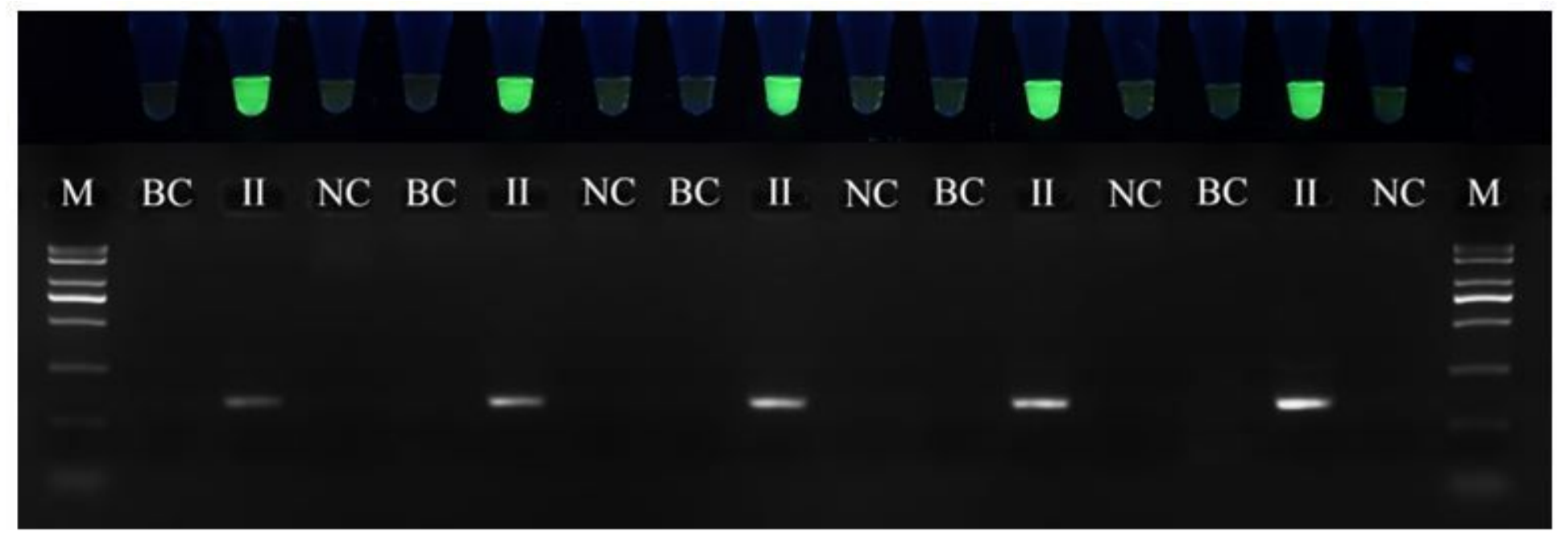

Figure 12

Investigate into the number of cycles of specific PCR systemin YN-II. The number of cycles was 26, 28, $30,32,34$, respectively.

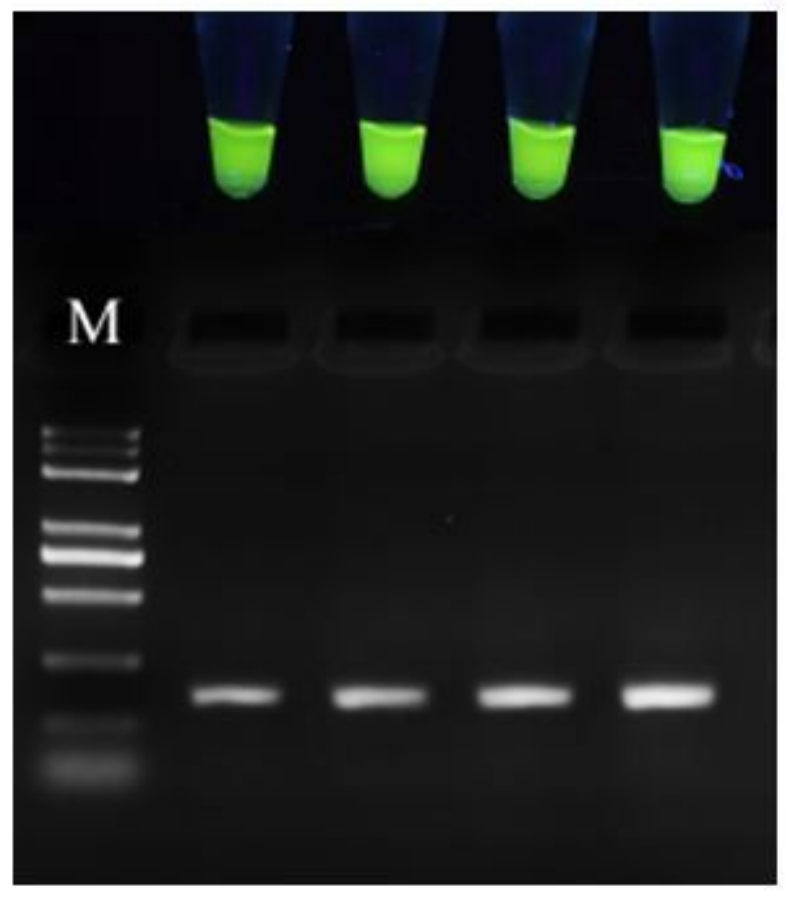

\section{Figure 13}

Investigate into the template quantities of specific PCR systemin YN-II. The template quantities were 10 ng, $30 \mathrm{ng}, 60 \mathrm{ng}$, and $90 \mathrm{ng}$, respectively. 


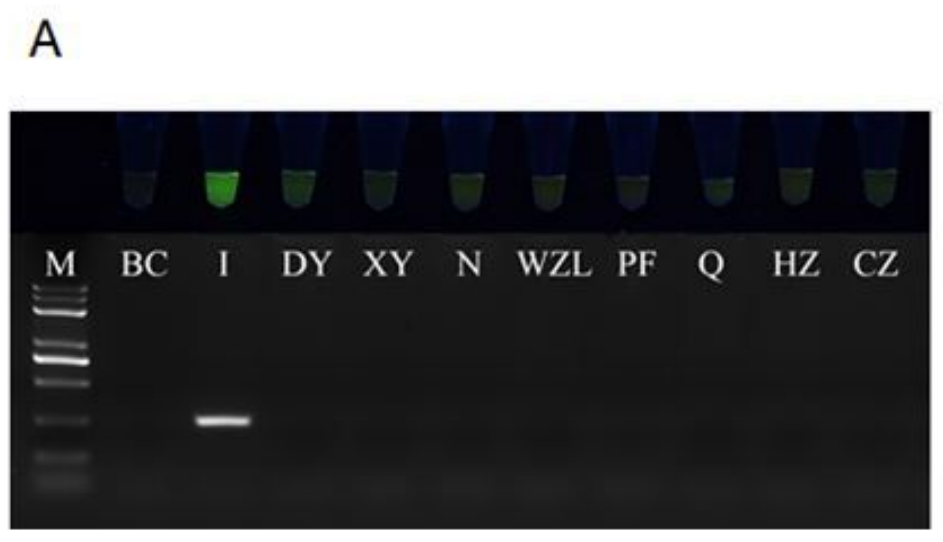

B

\section{Figure 14}

Fluorescent visualization identification of PPY with its common related species. (A) Specific identification of the YN-I system. (B) Specific identification of the YN-II system. M: Trans2K Plus DNA Marker. BC: blank control. I: PPY (YN-I). II: PPY (YN-II). DY: P. polyphylla. XY: P. stenophylla. N: P. vietnamensis. WZL: P. axialis. PF: P. vaniotii. Q:P. fargesii. HZ: P. thibetica. CZ:P. forrestii

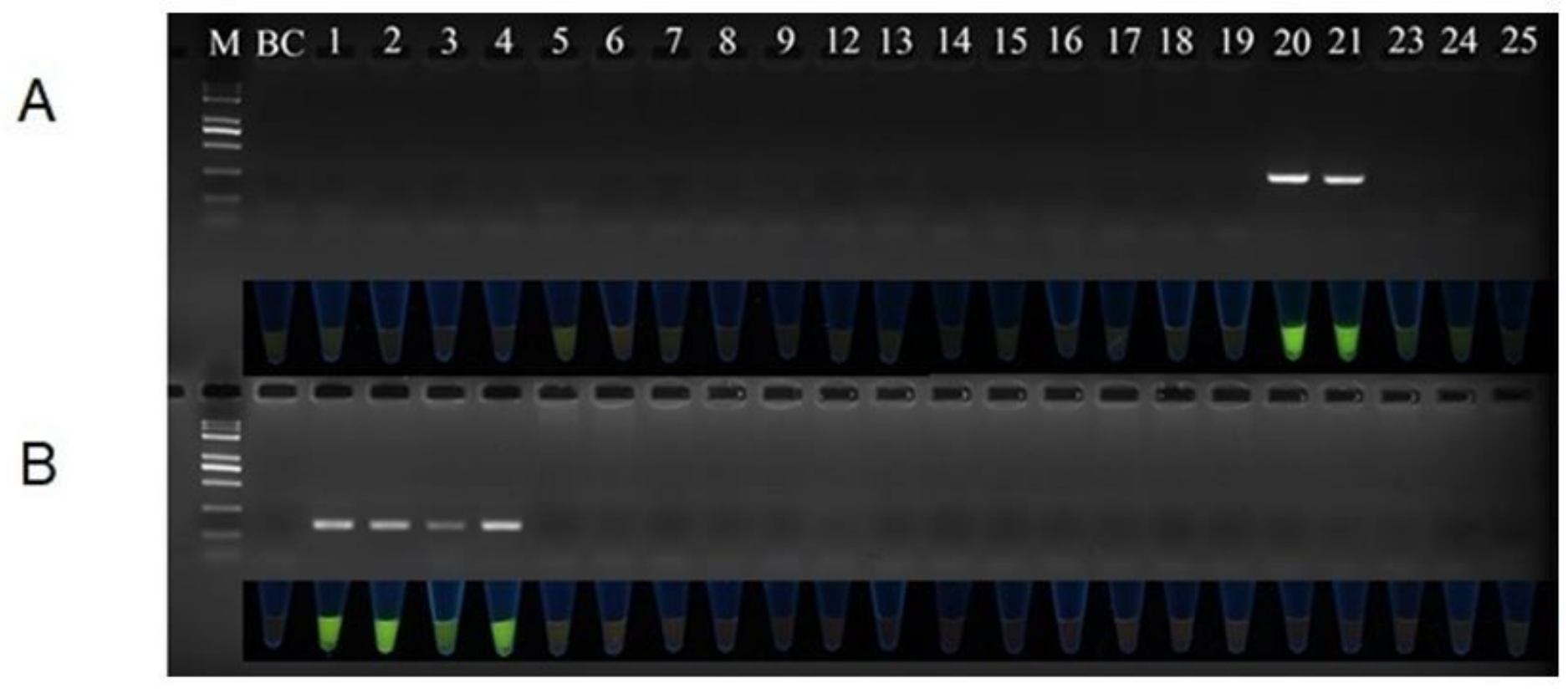

Figure 15

The specific identification of commercial medicinal materials of Paris. (A) The site-specific PCR system and fluorescence visual identification system of commercial medicinal materials of YN-I. (B) The sitespecific PCR system and fluorescence visual identification system of commercial medicinal materials of YN-II.

\section{Supplementary Files}


This is a list of supplementary files associated with this preprint. Click to download.

- SupplementaryMaterial.docx 